\title{
Molecular and morphometric changes in the small intestine during hot and cold exposure in thermally manipulated broiler chickens
}

\author{
Khaleel Emad Khaleel'(D), Mohammad Borhan Al-Zghoul1(D) and Khaled Musa Mohammad Saleh² (i) \\ 1. Department of Basic Medical Veterinary Sciences, Faculty of Veterinary Medicine, Jordan University of Science and \\ Technology, Jordan; 2. Department of Applied Biological Sciences, Faculty of Science and Art, Jordan University of \\ Science and Technology, Jordan. \\ Corresponding author: Mohammad Borhan Al-Zghoul, e-mail: alzghoul@just.edu.jo \\ Co-authors: KEK: kikhaleel18@vet.just.edu.jo, KMMS: khaledmousa93@gmail.com \\ Received: 06-01-2021, Accepted: 28-04-2021, Published online: 15-06-2021
}

doi: www.doi.org/10.14202/vetworld.2021.1511-1528 How to cite this article: Khaleel KE, Al-Zghoul MB, Saleh KMM (2021) Molecular and morphometric changes in the small intestine during hot and cold exposure in thermally manipulated broiler chickens, Veterinary World, 14(6): 1511-1528.

\begin{abstract}
Background and Aim: Thermal stress (hot or cold) is one of many environmental stressors that severely affects the health of broiler chickens. One negative effect of thermal stress is the disruption of the intestinal barrier function in broiler chickens. This study aimed to evaluate the effect of thermal manipulation (TM) on the small intestine in terms of histomorphometry as well as junctional, heat-shock, and immune response gene expression during post-hatch exposure to thermal stress.
\end{abstract}

Materials and Methods: The experiment was conducted by dividing 928 fertile Ross eggs into three incubation groups: The control (C) group (incubated at $37.8^{\circ} \mathrm{C}$ and $56 \%$ relative humidity [RH] for the whole incubation period), the TM using low temperature TML group (incubated at $36^{\circ} \mathrm{C}$ and $56 \% \mathrm{RH}$ for $18 \mathrm{~h} /$ day from embryonic days 7 to 16 ), and the TM using high temperature (TMH) group (incubated at $39^{\circ} \mathrm{C}$ and $65 \% \mathrm{RH}$ for $18 \mathrm{~h}$ /day from embryonic days 7 to 16 ). On post-hatch day 21, 90 chicks were randomly selected from each incubation group and were equally subdivided into three subgroups for the post-hatch thermal stress experiment: The TN subgroup (room temperature maintained at $24^{\circ} \mathrm{C}$ ), the heat stress (HS) subgroup (room temperature maintained at $35^{\circ} \mathrm{C}$ ), and the cold stress $(\mathrm{CS}$ ) subgroup (room temperature maintained at $16^{\circ} \mathrm{C}$ ). After 1 day of thermal stress exposure (age 22 days), five birds from each subgroup were euthanized and ileum samples were collected to evaluate the transcription of the Claudin (CLDN1), CLDN-5, Occludin, Cadherin-1, heat shock factors (HSF1), HSF3, 70 kilodalton heat shock protein, 90 kilodalton heat shock protein, Interleukin 6 (IL6), IL8, tolllike receptors-2 (TLR2), and TLR4 genes by Real-Time Quantitative Reverse Transcription polymerase chain reaction analysis. Finally, after 4 and 7 days of thermal stress (age 25 and 28 days, respectively), nine chicks were euthanized, and their jejunum and ileum were collected for histomorphometric analysis.

Results: After exposure to 1 day of thermal stress, the $\mathrm{C}$ subgroups exposed to thermal stress (HS and CS) possessed significantly increased expression of junctional, heat-shock, and immune response genes compared to the C-TN subgroup, and similar results were observed for the TMH. In contrast, thermally stressed TMH subgroups had significantly lower expression of the studied genes compared to $\mathrm{C}$ subgroups exposed to thermal stress. Furthermore, no significant changes were detected between the TML subgroups exposed to thermal stress and TML-TN. Moreover, significant alterations in villus height $(\mathrm{VH})$, villus surface area, crypt depth $(\mathrm{CD})$, and $\mathrm{VH}$ to $\mathrm{CD}$ ratio were observed between the TML, TMH, and C subgroups exposed to CS.

Conclusion: It might be suggested that TM may have a protective impact on the small intestine histomorphometry and epithelial integrity of broilers during post-hatch exposure to thermal stress.

Keywords: broilers, heat shock proteins, immune response, junctional proteins, thermal manipulation, thermal stress.

\section{Introduction}

The exposure of broiler chickens to non-optimal ambient temperatures is considered to be a kind of stress, as the ideal temperature range for broilers, that is, the thermoneutral zone, lies within the range of $18-22^{\circ} \mathrm{C}$ [1]. The exposure of chickens to an ambient temperature that is significantly higher or lower than that of the thermoneutral zone results in a thermal

Copyright: Khaleel, et al. Open Access. This article is distributed under the terms of the Creative Commons Attribution 4.0 International License (http://creativecommons.org/licenses/ by/4.0/), which permits unrestricted use, distribution, and reproduction in any medium, provided you give appropriate credit to the original author(s) and the source, provide a link to the Creative Commons license, and indicate if changes were made. The Creative Commons Public Domain Dedication waiver (http:// creativecommons.org/publicdomain/zero/1.0/) applies to the data made available in this article, unless otherwise stated. stress response, a term which refers to the non-organized physiological responses to extreme ambient temperatures that occur to maintain the body temperature (BT) within the ideal range for that organism $[1,2]$. Thermal stress arises due to the imbalance between the amount of net energy released from the body and the total heat produced by the body's metabolic processes $[2,3]$. Subsequently, thermal stress leads to a severe impact on poultry health and production, resulting in commercial losses that are exacerbated during the summer months [2,4-8].

The gastrointestinal tract is the largest part of the body that comes into contact with the external environment, and a sound intestinal barrier is integral in protecting the body from external threats [9]. The protective elements of the intestinal barrier are rooted in 
tight junction proteins, such as claudins $(C L D N)$ and occludins $(O C L N)$ as well as adherens junction proteins, such as cadherin $(C D H)$ [10]. Any damage to junctional proteins increases the permeability of the intestinal barrier to luminal antigens and may facilitate the translocation of pathogens across it, resulting in endogenous infection and eventual endotoxemia that impairs the absorption of nutrients [11,12]. The previous studies had reported that thermal stress could affect intestinal integrity by modulating the expression of junction and heat shock proteins in the small intestine of broiler chickens and subsequently increasing the expression of pro-inflammatory cytokines and toll-like receptors (TLR) [13-20]. In addition, thermal stress was reported to have severe effect on a broiler's nutrient absorption capability by modifying the intestine's histomorphometric parameters, leading to intestinal tissue injury [21-25].

Under thermal stress conditions, the cells respond to the extreme temperatures through a physiological response called heat shock response, which is a specific molecular response to acclimate to the extreme temperature [26]. Heat shock response is mediated through the upregulation and activation of a family of transcription factors called "heat shock factors (HSF)," such as HSF1 and HSF3, which mainly regulates the transcription of HSPs such as 70 kilodalton heat shock protein $(H S P 70)$ and 90 kilodalton heat shock protein (HSP90) $[27,28]$. The most studied HSP in terms of cellular protection from heat stress (HS) is $H S P 70$, as it can be considered to be anHS index in many organisms [29]. HSP possess a critical role in the cell, by their protection of denatured cellular proteins, since HSP correct the folding of damaged proteins, confer protection, prevent formation of protein aggregates, and promote cellular viability [30-32].

During embryonic development, manipulating the incubation temperature was suggested to improve post-hatch thermotolerance acquisition in a process commonly referred to as thermal manipulation (TM) [33-37]. TM enhances thermotolerance by epigenetic thermal adaptation, as the determination of the physiological control center's set point is highly affected by incubation temperature $[38,39]$. Previously, TM was reported to improve the small intestinal response to post-hatch thermal exposure by altering the expression of nutrient transporter genes as well as those genes involved in heat-shock, oxidative stress, and inflammatory response [40,41]. In addition, continuous TM from embryonic day 11 until hatching day alleviated the effect of post-hatch Salmonella Enteritidis infection on the small intestine by resulting in an increased villus height (VH), improved overall intestinal morphology, and enhanced HSP70 expression in the ileum [42]. However, the impact of cyclic TM (rather than continuous TM) on intestinal morphometry and integrity during post-hatch exposure to thermal stress is still unknown. Therefore, the aim of the present study is to evaluate the impact of cyclic
TM for $18 \mathrm{~h} /$ day during embryonic days $7-16$ on the morphometry of the jejunum and ileum (VH, villus width [VW], villus surface area [VSA], crypt depth [CD], and $\mathrm{VH}$ to $\mathrm{CD}$ ratio) and on the expression of junctional proteins (CLDN1, CLDN5, OCLN, and CDH1), heat shock proteins (HSP70, HSP90, HSF 1, and $H S F 3$ ), and immune response genes (TLR2, TLR4, Interleukin $6[I L 6]$, and $I L 8$ ) broiler ileums during post-hatch exposure to thermal stress.

\section{Materials and Methods}

\section{Ethical approval}

All procedures conducted in this study were approved by the Jordan University of Science and Technology (JUST) Animal Care and Use Committee.

\section{Study period and location}

Blood samples were collected from March 2019 to April 2020 at the Animal House Facility and Molecular Biology and Virology Laboratory, Faculty of Veterinary Medicine, Jordan University of Science and Technology, Jordan.

\section{Study population and incubation}

Figure-1 shows the summary of the experimental design executed in this study. A total of 1020 fertile eggs from the Ross broiler breed were obtained from certified distributors in Jordan (Amman, Jordan). The eggs were checked for any abnormality or breakage and 92 eggs were excluded. The eggs were divided into three incubation groups: The control group, the TM using low temperature (TML) group, and TM using high temperature (TMH) group. The eggs of the control group were incubated at $37.8^{\circ} \mathrm{C}$ and $56 \%$ relative humidity $(\mathrm{RH})$ throughout the embryogenesis period, while those of the TM groups were incubated as follows: TML group conditions were $36^{\circ} \mathrm{C}$ and $56 \% \mathrm{RH}$ for $18 \mathrm{~h}$ /day from days 7 to 16 of embryonic development, and TMH group conditions were $39^{\circ} \mathrm{C}$ and $65 \% \mathrm{RH}$ for $18 \mathrm{~h}$ /day from embryonic days 7 to 16 . RH in the TM treatment was elevated to $65 \%$ to prevent excessive water loss from the eggs that might result from their previously elevated incubation temperature.

On day 7 of embryonic development, the eggs were examined by candling: The infertile eggs and the eggs with dead embryos were removed. Commercial Type-I HS-SF incubators (Masalles, Barcelona, Spain) were used for egg incubation.

\section{Hatchery and post-hatch management}

On hatching day, the numbers of hatched chicks were recorded every $2 \mathrm{~h}$ to measure the early, late, and total hatchability rates. After hatching, the dried chicks were transported to the Animal House at JUST where the field experiments were performed. The chicks were randomly distributed into the cages into groups of 18 chicks per cage pen. Room temperature was maintained at $33 \pm 1^{\circ} \mathrm{C}$ during the $1^{\text {st }}$ week was gradually decreased to $21^{\circ} \mathrm{C}$ at the beginning of the $4^{\text {th }}$ week and was kept at $21^{\circ} \mathrm{C}$ until post-hatch day 


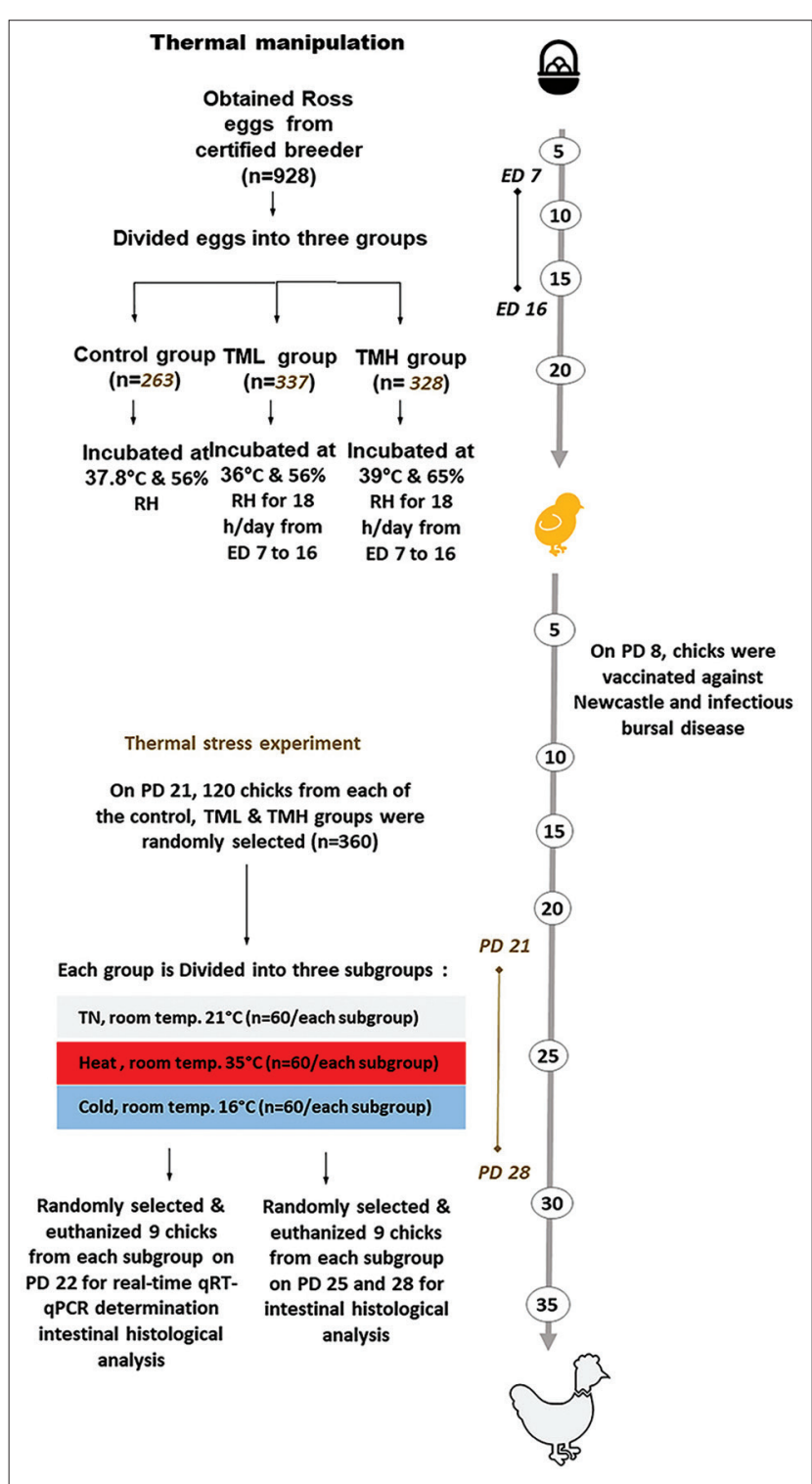

Figure-1: The summary of experimental design executed in the current study. ED=Embryonic day; $n=$ Numbers; PD $=$ Post-hatch day.

35. The BT and body weight (BW) were recorded on the following post-hatch days: $1,4,5,7,14,16,18$, $20,21,26,30,32$, and 35 . Water and appropriate feed were provided to the chicks ad libitum throughout the experimental period. The chicks were vaccinated against Newcastle disease and infectious bursal disease on post-hatch day 8 .

\section{Thermal stress experiment}

On post-hatch day 21, 120 chicks from each incubation group (control group, TML group, and TMH group) were randomly selected and further subdivided into three subgroups (thermal neutral [TN], cold stress [CS], and HS) to be used in the thermal stress experiment (for a duration of 7 days). For 7 days, TN subgroups were kept at $21^{\circ} \mathrm{C}, \mathrm{CS}$ subgroups were exposed to $16^{\circ} \mathrm{C}$, and $\mathrm{HS}$ subgroups were exposed to $35^{\circ} \mathrm{C}$. On days 1, 4, and 7 of the thermal stress experiments (post-hatch days 22, 25, and 28), nine chicks were randomly selected from each subgroup and their $\mathrm{T}^{\mathrm{b}}$ and BW were recorded. After 1 day of thermal stress, ileum samples were collected from each subgroup and snap-frozen for subsequent total RNA extraction. Then, the chicks exposed to 4 and 7 days of thermal stress were humanely euthanized to collect jejunum and ileum samples (about $1 \mathrm{~cm}$ ), which were maintained in a $10 \%$ neutral buffered formalin solution for histological morphometric evaluation.

\section{RNA extraction and cDNA synthesis}

Total RNA was extracted from the jejunum and ileum samples using Direct-Zol ${ }^{\mathrm{TM}}$ RNA MiniPrep (Zymo Research, Irvine, USA) with TRI Reagent ${ }^{\mathbb{B}}$ (Zymo Research, Irvine, USA) according to the protocol of the manufacturer. The RNA was quantified and qualified by Qubit 4 Fluorometer (Thermo Fisher Scientific, MA, USA), and Biotek PowerWave XS2 Spectrophotometer (BioTek Instruments, Inc., USA) and $1 \%$ agarose gel. $500 \mathrm{ng}$ of total RNA from each sample was used for cDNA synthesis using Prime Script RT Master Mix kit (Takara Bio Inc., Shiga, Japan).

\section{Relative mRNA quantitation analysis by real-time qPCR}

The QuantiFast SYBR ${ }^{\circledR}$ Green PCR Kit (Qiagen Corp., CA, USA) was used on a Rotor-Gene Q MDx 5 plex platform (QIAGEN Inc., CA, USA). Briefly, the $20 \mu \mathrm{L}$ reaction mix was prepared by adding $10 \mu \mathrm{L}$ of master mix, $1 \mu \mathrm{L}$ forward primer (10 pmol), $1 \mu \mathrm{L}$ reverse primer $(10 \mathrm{pmol}), 1 \mu \mathrm{L}$ cDNA from the sample, and $7 \mu \mathrm{L}$ of nuclease-free water. The PCR cycles employed the following parameters: $95^{\circ} \mathrm{C}$ for $5 \mathrm{~min}$; 40 cycles of $95^{\circ} \mathrm{C}$ for $10 \mathrm{~s}$ followed by $30 \mathrm{~s}$ annealing (Table-1 for details about annealing temperature); and $72^{\circ} \mathrm{C}$ for $10 \mathrm{~s}$ with final melting at $95^{\circ} \mathrm{C}$ for $20 \mathrm{~s}$. The detection of fluorescence emission occurred during the extension step. The $\beta$-actin gene was used as an internal control to which the fold changes in gene expression were normalized. The single target amplification specificity was approved by the melting curve. The relative quantitation was calculated using $2^{-\Delta \Delta \mathrm{Ct}}$ analysis. Table-1 shows primer sequences that were used in the real-time RT-qPCR analysis.

\section{Histological analysis}

After the fixation of the jejunum and ileum in a $10 \%$ neutral buffered formalin solution for histological evaluation, the organs were embedded in paraffin, cut to a thickness of 4-5 $\mu \mathrm{m}$ and stained with hematoxylin and eosin stains. Digital images were captured using a B-380 Optika microscope equipped with a C-P6 Pro camera and Optika ProView software (OPTIKA Microscopes, Ponteranica, Italy). Histological examinations were carried out according to the method performed by Shao et al. to determine VH, VW, VSA, $\mathrm{CD}$, and $\mathrm{VH}$ to $\mathrm{CD}$ ratio. VSA was calculated for each villus by multiplying the VH by the VW by $\pi$ [43].

\section{Statistical analysis}

All statistical analyses were conducted using IBM SPSS statistics software v.25 (IBM software, Chicago, 
Table-1: Primer sequences that are used in the real-time qPCR analysis

\begin{tabular}{|c|c|c|}
\hline Gene & Sequence $5^{\prime}-3^{\prime}$ & Annealing temperature ${ }^{\circ} \mathrm{C}$ \\
\hline$\beta$-actin & $\begin{array}{l}\text { F: ATGTGGATCAGCAAGCAGGAGTA } \\
\text { R: TTTATGCGCATTATGGGTITGT }\end{array}$ & 59 \\
\hline Claudin-1 & $\begin{array}{l}\text { F: CTGATTGCTTCCAACCAG } \\
\text { R: CAGGTCAAACAGAGGTACAGG }\end{array}$ & 56 \\
\hline Claudin-5 & $\begin{array}{l}\text { F: CATCACTTCTCCTTCGTCAGC } \\
\text { R: GCACAAAGATCTCCCAGGTC }\end{array}$ & 56 \\
\hline E-cadherin & $\begin{array}{l}\text { F: GACAGGGACATGAGGCAGAA } \\
\text { R: GCCGTGACAATGCCATTCTC }\end{array}$ & 57 \\
\hline HSF1 & $\begin{array}{l}\text { F: CAGGGAAGCAGTTGGTTCACTACACG } \\
\text { R: CCTTGGGTTTGGTTGCTCAGTC }\end{array}$ & 63 \\
\hline HSF3 & $\begin{array}{l}\text { F: TCCACCTCTCCTCTCGGAAG } \\
\text { R: CAACAGGACTGAGGAGCAGG }\end{array}$ & 57 \\
\hline HSP70 & $\begin{array}{l}\text { F: TCTCATCAAGCGTAACACCAC } \\
\text { R: TCTCACCTTCATACACCTGGAC }\end{array}$ & 55 \\
\hline HSP9O & $\begin{array}{l}\text { F: ATGCCGGAAGCTGTGCAAACACAGGACCAA } \\
\text { R: GGAATCAGGTTAATTTCAGGTCTTTCCA }\end{array}$ & 62 \\
\hline$I L-6$ & $\begin{array}{l}\text { F: GCTCGCCGGCTTCGA } \\
\text { R: GGTAGGTCTGAAAGGCGAACAG }\end{array}$ & 57 \\
\hline$I L-8$ & $\begin{array}{l}\text { F: CACGTTCAGCGATTGAACTC } \\
\text { R: GACTTCCACATTCTTGCAGTG }\end{array}$ & 59 \\
\hline Occludin & $\begin{array}{l}\text { F: ACGGCAGCACCTACCTCAA } \\
\text { R: GGGCGAAGAAGCAGATGAG }\end{array}$ & 59 \\
\hline$T L R-2$ & $\begin{array}{l}\text { F: CCTGCAACGGTCACTTCAG } \\
\text { R: GTCTCAGGGCTTGTTCTTCAG }\end{array}$ & 58 \\
\hline$T L R-4$ & $\begin{array}{l}\text { F: CTGACCTACCCATCGGACAC } \\
\text { R: GCCTGAGAGAGGTCAGGTTG }\end{array}$ & 58 \\
\hline
\end{tabular}

USA). $\mathrm{T}^{\mathrm{b}}$, BW and HSP90, HSP70, HSF1, HSF3, IL6, IL8, TLR2, TLR4, CLDN1, CLDN5, CDH1, and $O C L N$ mRNA levels were expressed as means \pm SD. However, VH, VW, VSA, CD, and $\mathrm{VH}$-to-CD ratio were expressed as means \pm SEM. One-way analysis of variance followed by all-pairs Bonferroni test was used to compare different parameters in all treatment groups, while the Chi-squared test was also used to compare the hatchability rates between the different incubation groups. Parametric differences were considered statistically significant at $\mathrm{p}<0.05$.

\section{Results}

\section{Impact of TM on broiler hatchability}

Table-2 lists the early, late, and total hatchability rates of broiler chickens subjected to embryonic TM. The TML group possessed a significantly lower hatchability rate on embryonic day $20(\mathrm{p}<0.05)$ and significantly higher hatchability rate on embryonic day 22 compared to the control and TMH groups $(\mathrm{p}<0.05)$. In contrast, the TMH group had a significantly higher hatchability rate on embryonic day 20 and a significantly lower one on embryonic day 21 with respect to the control group $(\mathrm{p}<0.05)$. However, TM did not have a significant effect on the total hatchability rate.

\section{Effect of TM on broiler BW}

Figure-2 represents the effect of embryonic TM on the post-hatch BW of broiler chickens. TML significantly decreased BW in all post-hatch days $(\mathrm{p}>0.05)$ except for days 16, 21, 30, 32, and 35. Contrastingly, the TMH group exhibited significantly increased BW on post-hatch days $4,14,16,32$, and 35 compared to the control group $(\mathrm{p}>0.05)$.
Table-2: Effect of thermal manipulation (TM) during embryogenesis on the hatchability rates of broiler chickens

\begin{tabular}{lccc}
\hline & Control & TML & TMH \\
\hline $\begin{array}{l}\text { Total eggs } \\
\text { Hatched on ID 20 } \\
\text { (hatchability \%) }\end{array}$ & $81(31)^{\mathrm{a}}$ & $14(4)^{\mathrm{b}}$ & $209(64)^{\mathrm{c}}$ \\
$\begin{array}{l}\text { Hatched on ID 21 } \\
\text { (hatchability \%) }\end{array}$ & $164(62)^{\mathrm{a}}$ & $100(30)^{\mathrm{b}}$ & $92(28)^{\mathrm{b}}$ \\
$\begin{array}{l}\text { Hatched on ID 22 } \\
\text { (hatchability \%) }\end{array}$ & $0(0)^{\mathrm{a}}$ & $203(60)^{\mathrm{b}}$ & $0(0)^{\mathrm{a}}$ \\
$\begin{array}{l}\text { Total hatched } \\
\text { Hatchability \% }\end{array}$ & 245 & 317 & 301 \\
\hline
\end{tabular}

${ }^{a-c}$ within the same row, values with different superscripts indicate significant differences $(P<0.05)$.

ID: incubation day

\section{Effect of TM on broiler BT $\left(\mathrm{T}^{\mathrm{b}}\right)$}

Figure-3 depicts the effect of embryonic TM on the post-hatch $\mathrm{T}^{\mathrm{b}}$ of broiler chickens. When compared to the control, the TML group had significantly lower $\mathrm{T}^{\mathrm{b}}$ on post-hatch day 1 and significantly higher $\mathrm{T}^{\mathrm{b}}$ on days 14 and $21(\mathrm{p}<0.05)$. Except for post-hatch days 7 and 14 , the $\mathrm{T}^{\mathrm{b}}$ of $\mathrm{TMH}$ group was significantly higher than those of control group $(p>0.05)$; there was no significant difference in $\mathrm{T}^{\mathrm{b}}$ compared to the other treatment groups.

\section{Effect of heat and cold exposure on BW of TM broilers}

Figure-4a and $\mathrm{b}$ depict the effect of heat and cold exposure for 7 days (post-hatch days 21-28) on the $\mathrm{BW}$ of TM broilers.

\section{TML group}

No significant difference was observed in the BW of the TML group compared to those of the control group during heat exposure. However, the BW of 


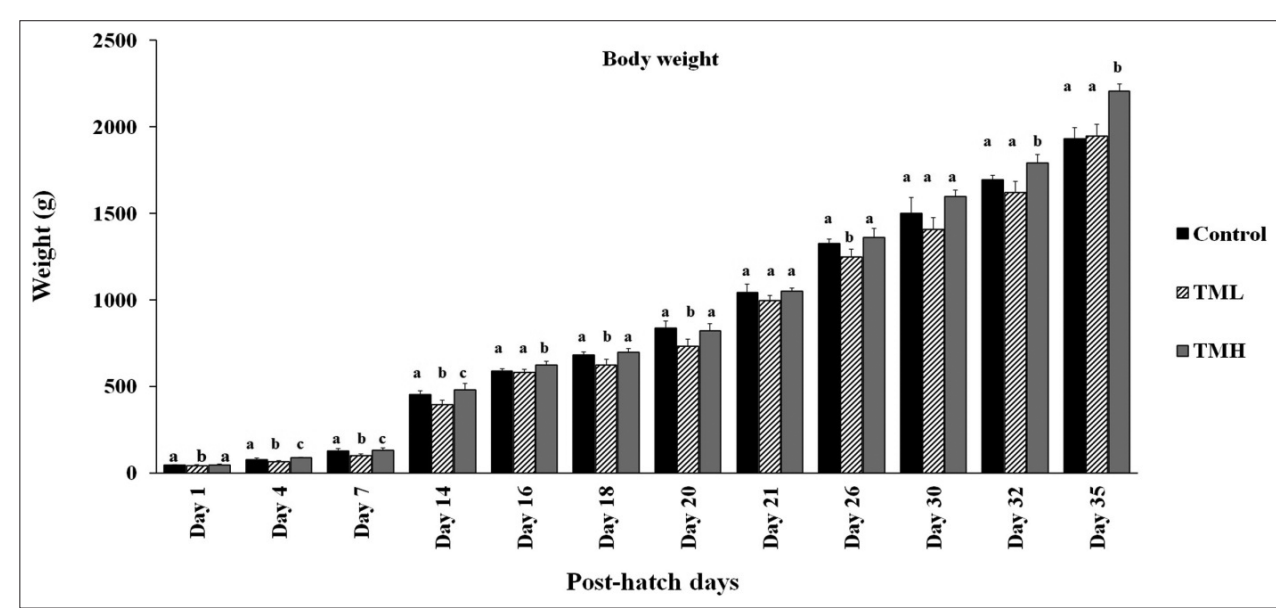

Figure-2: Effects of thermal manipulation (TM) during embryogenesis on post-hatch body weight (BW) of broiler chicks $(n=15){ }^{a-c}$ within the same day, means \pm SD with different superscripts is significantly different $(p<0.05)$.

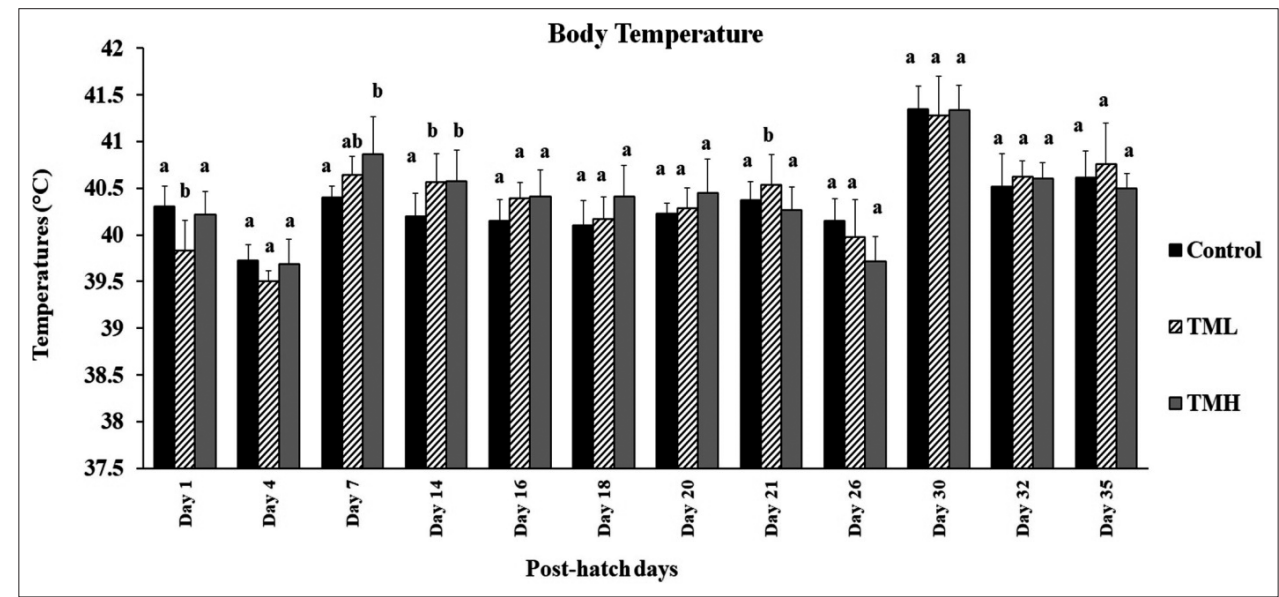

Figure-3: Effects of thermal manipulation (TM) during embryogenesis on post-hatch body temperature $\left(T^{b}\right)$ of broiler chicks $(n=15)$. a,b within the same day, means \pm SD with different superscripts are significantly different $(p<0.05)$.

the TML group was significantly lower under TN conditions compared to the TML group exposed to 7 days of HS ( $\mathrm{p}<0.05)$. In addition, under CS, the TML group possessed significantly lower BW compared to the control group exposed to CS and compared to the TML group exposed to TN conditions $(\mathrm{p}<0.05)$.

\section{TMH group}

On the other hand, the $\mathrm{BW}$ of the TMH group exposed to HS was significantly lower compared with that of the TMH group exposed to TN conditions after 1 and 4 days of the heat exposure $(p<0.05)$. However, the BW of both groups was not significantly different on the $7^{\text {th }}$ day of HS. Furthermore, under HS, the BW of TMH group was significantly higher than that of control group on the $7^{\text {th }}$ day of heat exposure $(p<0.05)$.

\section{Effect of heat and cold exposure on BT of TM broilers}

Figure-5a and $b$ depict the effect of heat and cold exposure for 7 days (post-hatch days 21-28) on the BT of TM broilers.

\section{TML group}

Under HS, the TML group had a significantly lower BT than the control group on days 1 and 4 of heat exposure $(\mathrm{p}<0.05)$. In addition, the TML group exposed to HS had significantly higher BT than the TML group kept under TN conditions $(\mathrm{p}<0.05)$. Under cold exposure, the TML group did not show a significant difference in BT compared to the control group. However, the TML group exposed to CS possessed significantly lower BT than the TML group kept under TN conditions on day 1 of cold exposure, but it was significantly higher on day 7 of cold exposure $(\mathrm{p}<0.05)$.

\section{TMH group}

The BT of the TMH group was significantly higher on day 7 of heat exposure compared to the TMH group exposed to TN condition $(p<0.05)$. However, the BT of the TMH group was significantly lower than that of the control group under HS conditions $(p<0.05)$. No significant difference in BT was detected between the TMH and control groups exposed to CS. In contrast, compared with the TMH group kept under TN condition, the TMH group exposed to CS possessed significantly lower BT after 1 day and significantly higher BT after 7 days of cold exposure $(\mathrm{p}<0.05)$. 


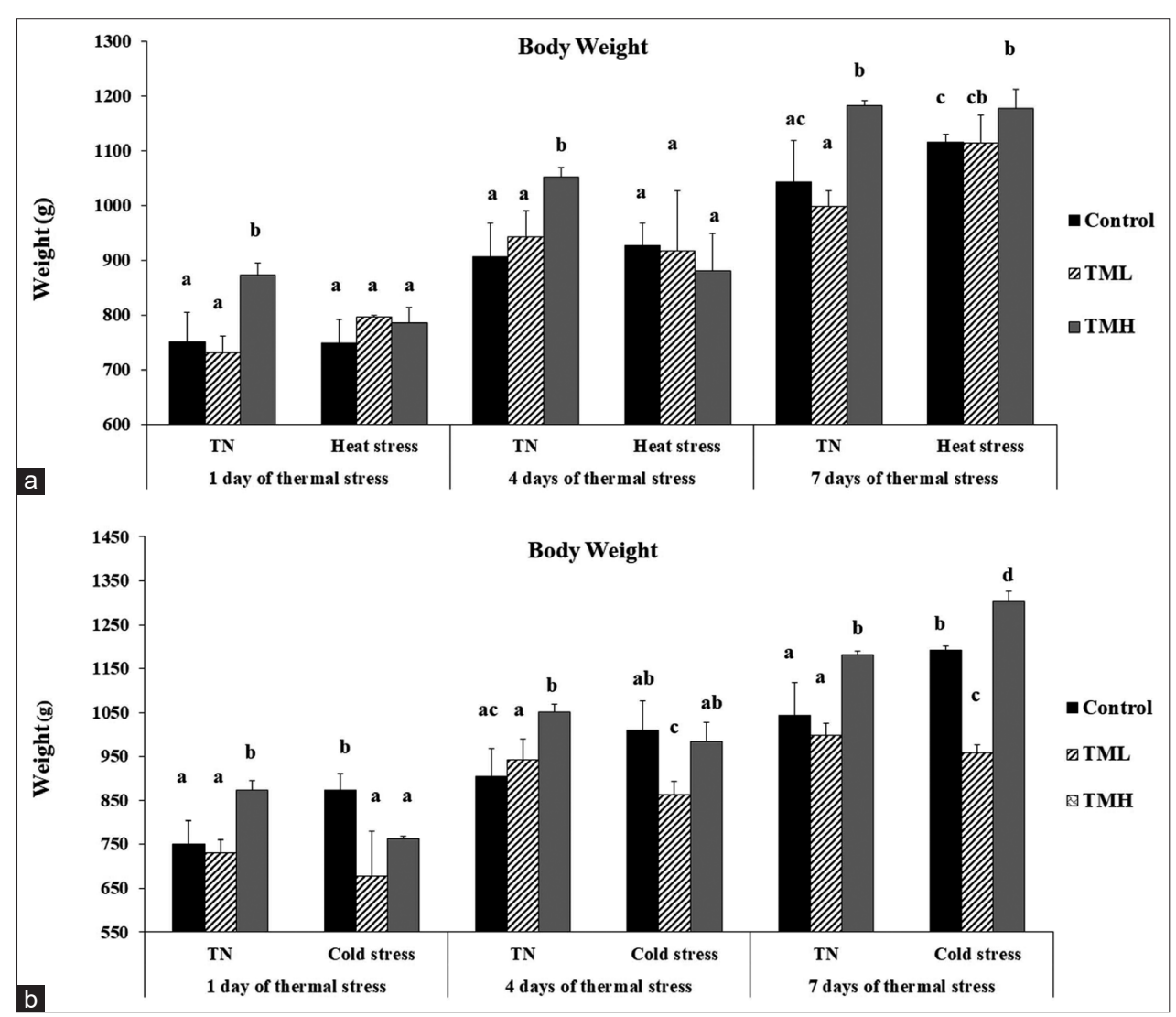

Figure-4: Effects of heat (a) and cold (b) exposures for 7 days (post-hatch days 21-28) on body weight (BW) of broiler chicks subjected to thermal manipulation (TM) during embryogenesis $(n=15)$. a-d within the same day, means \pm SD with different superscripts is significantly different $(\mathrm{p}<0.05)$. TN=Thermal neutral, $\mathrm{CHS}=$ Chronic heat stress, CCS $=$ Chronic cold stress.

\section{Effect of heat and cold exposure on the mRNA Levels} of junctional proteins in the ileum of TM broilers

Figure-6 depicts the effect of 1-day heat and cold exposure on the mRNA levels of the CLDN1, CLDN5, $C D H 1$, and $O C L N$ genes in the ileum of TM broiler chicks.

\section{CLDN1}

Under TN, heat, and cold exposure, CLDN1 expression was significantly decreased in the TML group compared to the control $(\mathrm{p}<0.05)$. In addition, the TMH group led to a significantly lower $C L D N 1$ expression compared to the controls only during TN condition $(p<0.05)$. However, the TMH groups exposed to heat and cold exposures exhibited significantly higher $C L D N 1$ expression compared to the TMH group kept under $\mathrm{TN}$ condition $(\mathrm{p}<0.05)$. In contrast, CLDN1 expression was not significantly different among TML groups under TN, heat, and cold exposures.

\section{CLDN5}

The TML group had significantly lower CLDN5 expression compared to the control group under both heat and cold exposures $(\mathrm{p}<0.05)$, while no significant difference was observed in CLDN5 expression of the TMH group compared to the control. On the other hand, the control group exposed to HS had significantly higher $C L D N 5$ expression than the control group kept under TN condition $(\mathrm{p}<0.05)$. Moreover,
TMH groups under heat and cold exposures showed significantly higher $C L D N 5$ expression compared to the TMH group kept under TN condition $(\mathrm{p}<0.05)$. However, no significant change was detected in CLDN5 expression between the TML groups under $\mathrm{TN}$, heat, and cold exposures.

\section{$\mathrm{CDH1}$}

Under HS, the TML group had significantly lower $\mathrm{CDH1}$ expression compared to the control group $(\mathrm{p}<0.05)$, but under TN and cold exposures, no significant difference between the TML and control groups was detected $(\mathrm{p}>0.05)$. Furthermore, no significant change in the $\mathrm{CDH}$ l expression was detected between the TMH and control groups under TN, heat, and cold exposures.

\section{$O C L N$}

OCLN expression under TN and HS conditions was significantly lower in the TML group compared with the control group $(\mathrm{p}<0.05)$, while no significant difference was observed between the TML and control groups under cold exposure. Moreover, no significant difference was observed between the TMH and control groups under $\mathrm{TN}$, heat, and cold exposures.

\section{Effect of heat and cold exposure on the mRNA levels} of heat shock proteins in the ileum of TM broilers

Figure-7 depicts the effect of 1-day heat and cold exposure on the mRNA levels of heat shock proteins 


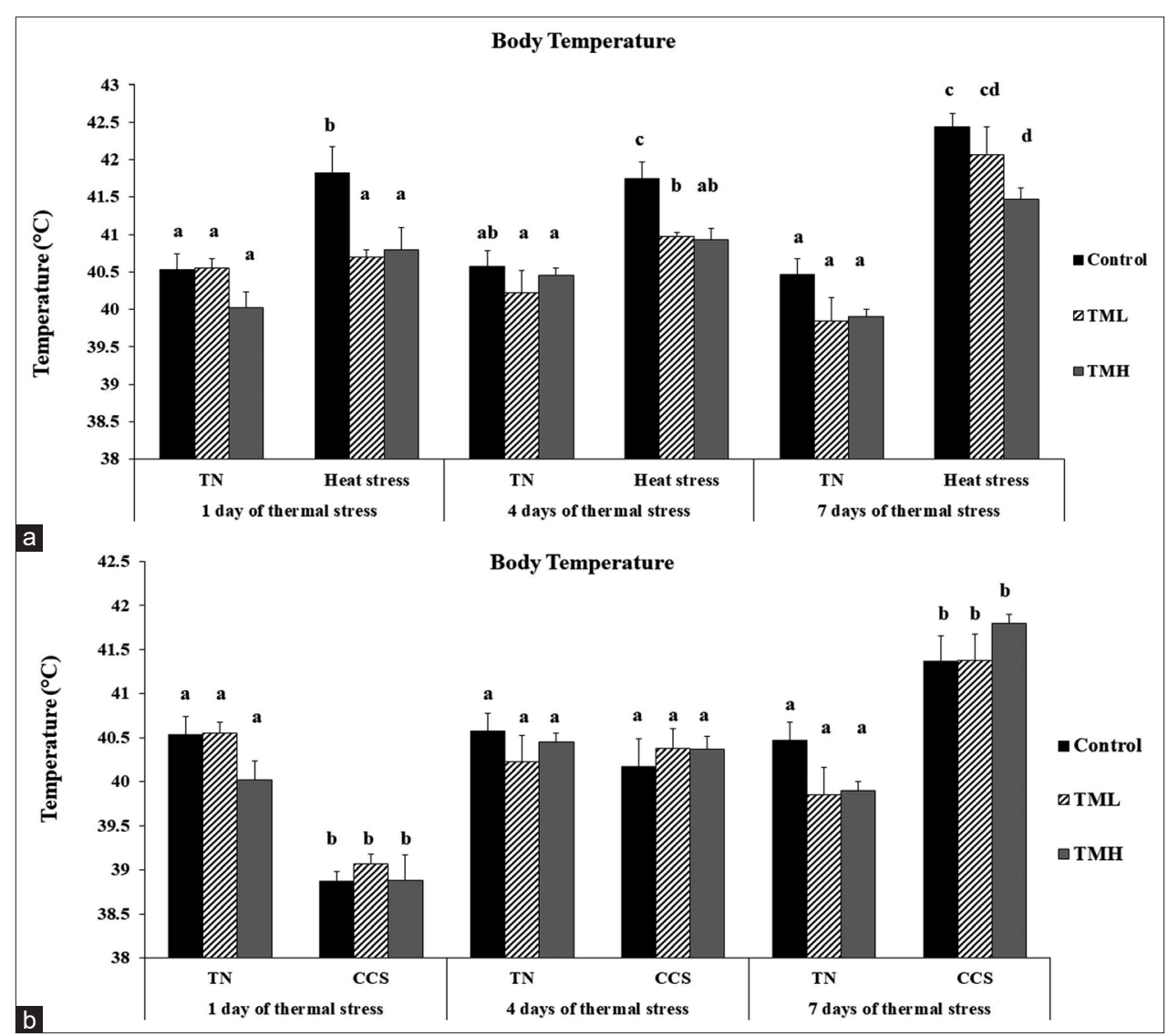

Figure-5: Effects of heat (a) and cold (b) exposures for 7 days (post-hatch days 21-28) on body temperature ( $T^{\mathrm{b}}$ ) of broiler chicks subjected to thermal manipulation (TM) during embryogenesis $(n=15)$. a-d within the same day, means $\pm S D$ with different superscripts is significantly different $(\mathrm{p}<0.05)$. TN=Thermal neutral, CHS=Chronic heat stress, CCS $=$ Chronic cold stress.

(HSF1, HSF3, HSP90, and HSP70) in the ileum of TM broiler chicks.

\section{HSF 1}

Under TN, heat, and CS conditions, the TML group exhibited significantly lower $H S F 1$ expression compared to the control group $(\mathrm{p}<0.05)$. The TMH group showed significantly lower $H S F 1$ expression compared to controls under heat exposure $(\mathrm{p}<0.05)$, while no difference between them was detected under $\mathrm{TN}$ and cold exposures $(\mathrm{p}>0.05)$. In addition, the control group kept under TN condition had significantly lower HSF1 expression than the control group exposed to HS $(p<0.05)$. Similarly, the TML group kept under TN conditions possessed significantly lower $H S F 1$ expression than the TML group exposed to HS $(\mathrm{p}<0.05)$. Furthermore, the TMH group kept under TN conditions had significantly lower HSF1 expression than the TMH groups under both heat and cold exposures $(\mathrm{P}<0.05)$.

\section{HSF3}

Under both heat and cold exposures, the TML group had significantly lower HSF3 expression with respect to controls $(\mathrm{p}<0.05)$. In contrast, the $\mathrm{TMH}$ group possessed significantly lower HSF3 expression compared to controls only under heat exposure $(p<0.05)$. On the other hand, the control group kept under TN conditions had significantly lower $H S F 3$ expression compared to control groups exposed to heat and CS $(\mathrm{p}<0.05)$, and similar results were observed for the TMH group. However, HSF3 expression in the TML group exposed to TN conditions was not significantly different from the TML groups exposed to both heat and CS).

\section{HSP70}

Under TN conditions, the TML group had significantly increased $H S P 70$ expression compared to the control group $(\mathrm{p}<0.05)$. However, under both heat and cold exposures, the TML group had significantly lower $H S P 70$ expression with respect to controls $(p<0.05)$. Under heat exposure, the TMH group exhibited significantly lower HSP70 expression compared to controls $(\mathrm{p}<0.05)$. However, no significant difference was observed between the TMH and control groups under both TN and cold exposures. On the other hand, control groups exposed to both heat and cold conditions had significantly increased $H S P 70$ expression compared to the control group kept under TN condition $(\mathrm{p}<0.05)$. Similar results were observed for the TMH group, but no significant change in HSP70 expression was observed between the TML groups under TN, heat, and CS conditions. 


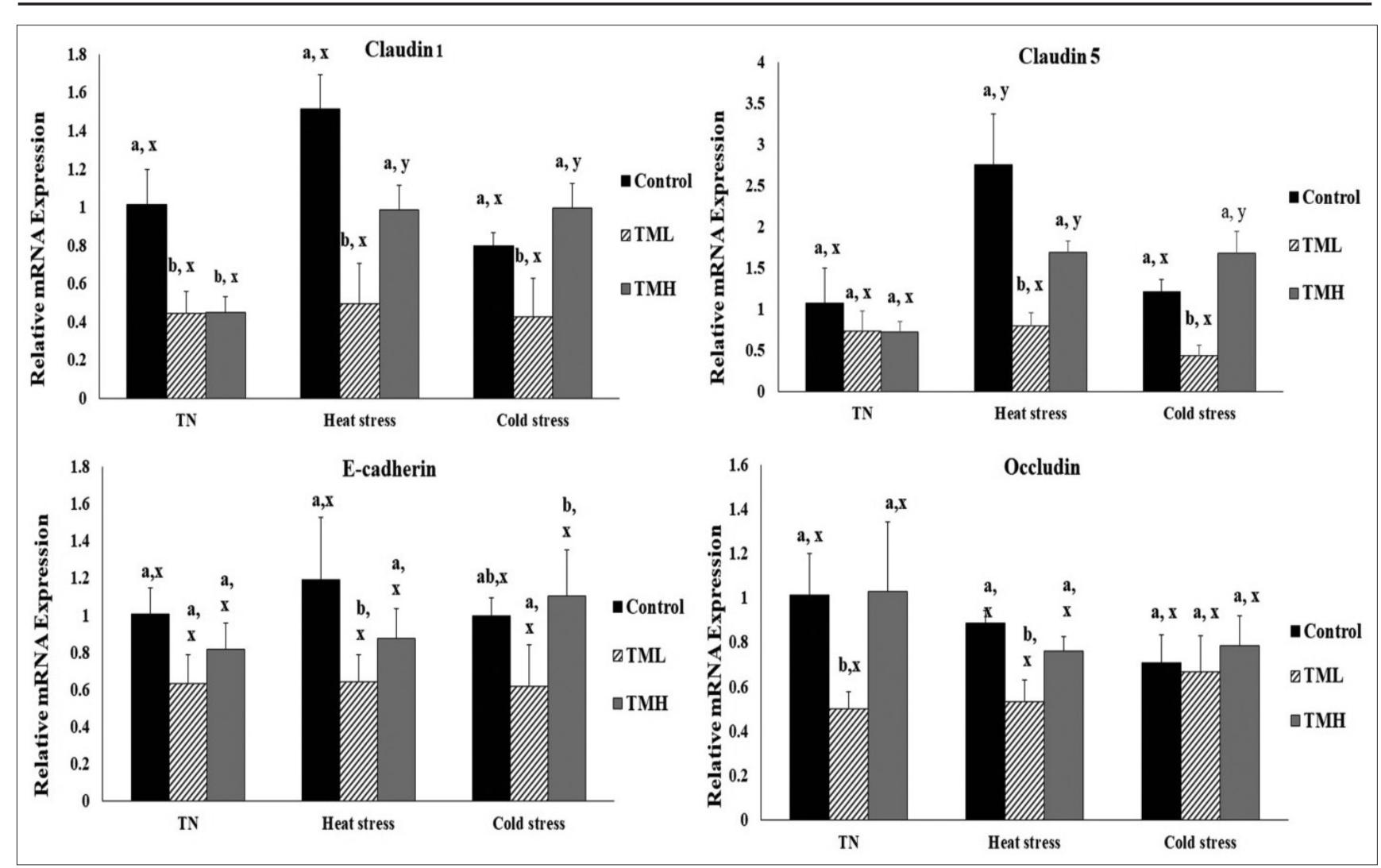

Figure-6: Effects of heat and cold exposures for 1 day on the mRNA levels of junctional proteins (CLDN, CLDN, E-CDH, and $O C L N)$ in the ileum of broiler chicks subjected to thermal manipulation (TM) during embryogenesis $(n=5)$. The values in the chart indicate folds of mRNA level in the control group-TN. a,b within the same condition (either TN, heat or cold stress) and between different incubation groups (control, $T M L$, and $T M H$ ), means \pm SD with different superscripts are significantly different $(p<0.05)$. ${ }^{x, y}$ within the same incubation group but between $T N$, heat, and cold exposures, means \pm SD with different superscripts are significantly different $(p<0.05)$.

\section{HSP90}

HSP90 expression was significantly increased in the control group exposed to heat and cold conditions compared to that in the control group kept under TN conditions $(\mathrm{p}<0.05)$. However, HSP90 expression in the TML and TMH groups was not significantly changed between the TN, heat, and cold exposure conditions. Furthermore, HSP90 expression was significantly lower in the TMH group than in control group under cold exposure $(\mathrm{p}<0.05)$.

Effect of heat and cold exposure on the mRNA levels of immune-related genes in the ileum of TM broilers

Figure- 8 represents the effect of 1-day heat and cold exposure on the mRNA levels of toll-TLR (TLR2 and TLR4) and pro-inflammatory cytokines (IL6 and $I L 8)$ in the ileum of TM broiler chicks.

\section{TLR2}

$T L R 2$ expression in the TMH group was significantly higher than that in control group under TN conditions $(p<0.05)$. Under heat and cold exposures, TLR 2 expression in the TML group was significantly lower than that in control group $(\mathrm{p}<0.05)$. In addition, TLR 2 expression in the control group was significantly increased under heat and cold exposures compared to that under $\mathrm{TN}$ condition $(\mathrm{p}<0.05)$.

\section{TLR4}

Under heat and cold exposures, TLR4 expression was significantly lower in the TML group than in the control group $(\mathrm{p}<0.05)$. Furthermore, TLR 4 expression was significantly lower in the TMH group compared to that in the control group under HS conditions $(\mathrm{p}<0.05)$. Moreover, TLR4 expression in both the TMH and control groups exposed to $\mathrm{TN}$ conditions was significantly lower than that in the TMH and control groups under heat and under CS conditions $(\mathrm{p}<0.05)$. However, TLR4 expression in the TML group kept under TN condition was significantly higher than that in TML group exposed to CS $(\mathrm{p}<0.05)$.

\section{IL6}

IL6 expression in the TML group was significantly lower than that in the control group during both heat and cold exposures $(p<0.05)$. On the other hand, IL6 expression was significantly lower in the control and TMH groups kept under TN conditions than that in counterpart groups exposed to both heat and CS conditions $(\mathrm{p}<0.05)$.

\section{IL8}

IL8 expression was significantly lower in the TML group compared to that in the control group during heat exposure $(\mathrm{p}<0.05)$. In addition, IL 8 expression was 


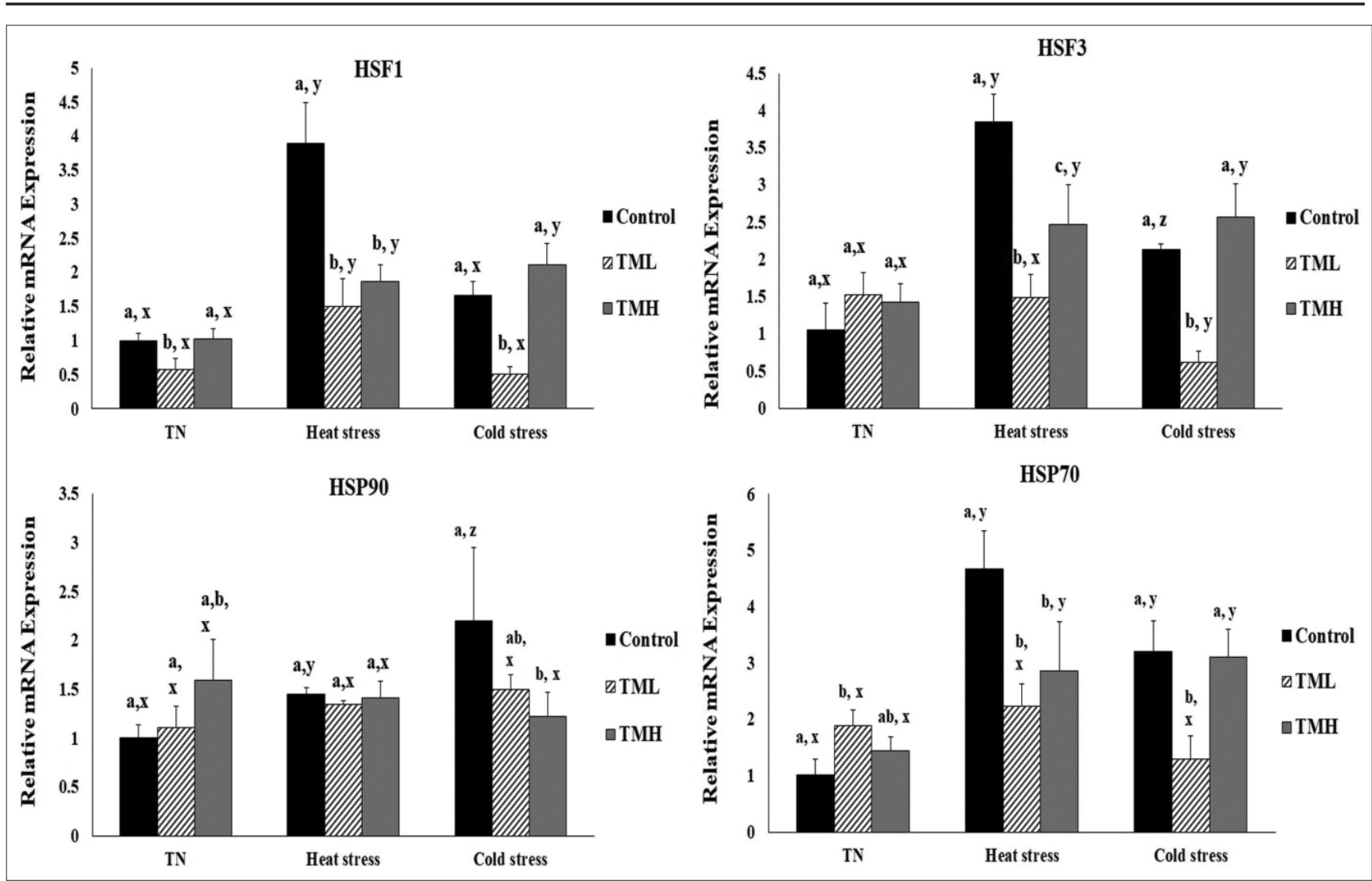

Figure-7: Effects of heat and cold exposures for 1 day on the mRNA levels of heat shock proteins (HSF1, HSF3, HSP90, and HSP70) in the ileum of broiler chicks subjected to thermal manipulation (TM) during embryogenesis $(n=5)$. The values in the chart indicate folds of mRNA level in the control group-TN. a-c within the same condition (either TN, heat, or cold stress) and between different incubation groups (control, TML, and TMH), means \pm SD with different superscripts is significantly different $(p<0.05) . x, z$ within the same incubation group but between TN, heat, and cold exposures, means \pm SD with different superscripts are significantly different $(p<0.05)$.

significantly lower in the control and TMH groups kept under TN conditions compared to that in the counterpart groups exposed to heat and cold exposures $(\mathrm{p}<0.05)$. Finally, IL8 expression was significantly lower in the TML group kept under TN condition than that in the counterparts exposed to CS $(\mathrm{p}<0.05)$.

\section{Effect of heat and cold exposures on the morphology of the small intestines of TM broilers}

Figure-9 depicts microscopic measurements of $\mathrm{VH}, \mathrm{VW}$, and $\mathrm{CD}$ for both the jejunum and ileum.

\section{Impact of 4-day thermal exposure on ileum morphology}

Table-3 represents the effect of 4-day heat and cold exposures (post-hatch days 21-25) on the morphology of the ileum in TM broiler chicks. No significant changes were observed in the VH, VW, VSA, CD, and $\mathrm{VH}$ : $\mathrm{CD}$ ratio between the different groups in the ileum after 4 days of heat and cold exposure ( $p>0.05)$.

\section{Impact of 4-day thermal exposure on jejunum morphology}

Table-4 displays the effects of 4-day heat and cold exposures (post-hatch days 21-25) on the morphology of the jejunum in TM broiler chicks. No significant changes were detected in the $\mathrm{VH}, \mathrm{VW}, \mathrm{VSA}, \mathrm{CD}$, and $\mathrm{VH}$ : CD ratio between the control, TML and TMH groups under TN and HS conditions. During CS, the VH, VSA, and VH: CD ratio were significantly higher in the TML and TMH groups exposed to CS compared to that in the TML and TMH groups kept under TN conditions $(p<0.05)$. In addition, significant increases in the $\mathrm{VH}$ and $\mathrm{CD}$ were observed in the control group exposed to CS with respect to that exposed to TN conditions $(p<0.05)$. Furthermore, under CS, the TMH group had significantly lower $\mathrm{CD}$ than the control group, and the TML and TMH groups had significantly higher $\mathrm{VH}$ : CD ratio than the control group $(\mathrm{p}<0.05)$.

\section{Impact of 7-day thermal exposure on ileum morphology}

Table-5 represents the effects of 7-day heat and cold exposures (post-hatch days 21-28) on the morphology of the ileum in TM broiler chicks. No significant changes were observed in the $\mathrm{VH}, \mathrm{VW}$, and VSA between the control, TML and TMH groups under different conditions. However, the $\mathrm{CD}$ was significantly higher and the $\mathrm{VH}$ : $\mathrm{CD}$ ratio was significantly lower in the control group exposed to TN conditions than that in the control exposed to heat and cold exposures $(\mathrm{p}<0.05)$.

\section{Impact of 7-day thermal exposure on jejunum morphology}

Table-6 represents the effects of 7-day heat and cold exposures (post-hatch days 21-28) on the 


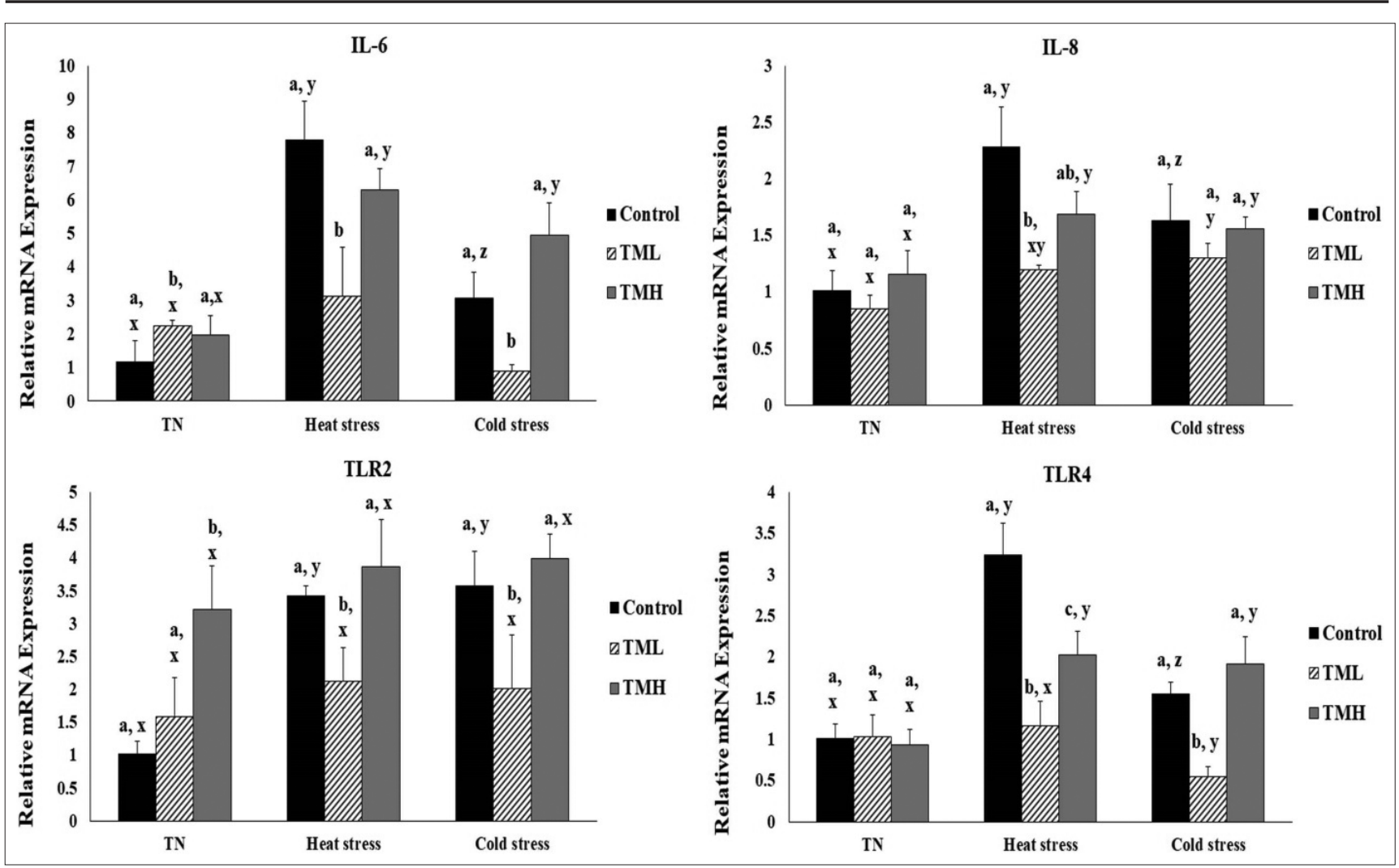

Figure-8: Effects of heat and cold exposures for 1 day on the mRNA levels of toll-like receptors (TLR2 and TLR-4) and pro-inflammatory cytokines (IL-6 and $I L-8)$ in the ileum of broiler chicks subjected to thermal manipulation (TM) during embryogenesis $(n=5)$. The values in the chart indicate folds of mRNA level in the control group-TN. ${ }^{a-c}$ within the same condition (either TN, heat, or cold stress) and between different incubation groups (control, TML, and TMH), means \pm SD with different superscripts is significantly different $(p<0.05) .{ }^{x, z}$ within the same incubation group but between TN, heat, and cold exposures, means \pm SD with different superscripts are significantly different $(p<0.05)$.

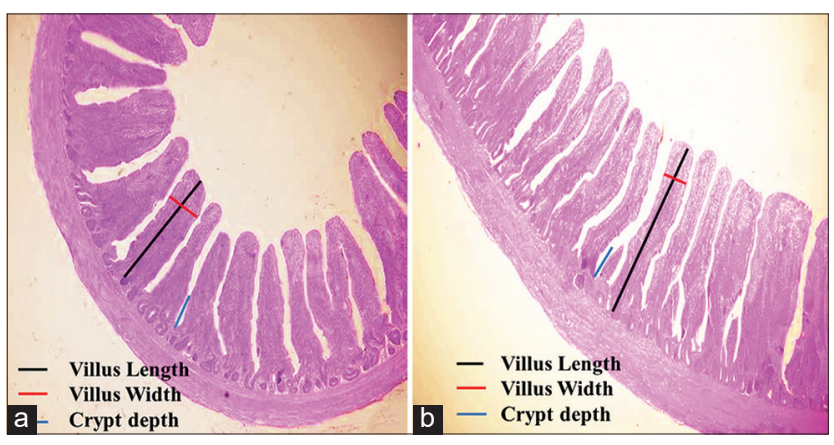

Figure-9: ( $a$ and $b)$ Depicts the microscopic measurements of $\mathrm{VH}, \mathrm{VW}$, and $\mathrm{CD}$ for both jejunum and ileum. $\mathrm{VH}=$ Villus height, $\mathrm{VW}=$ Villus width, $\mathrm{VSA}=$ Villus surface area, $C D=$ Crypt depth, $\mathrm{VH}: \mathrm{CD}=$ Villus height to crypt depth ratio.

morphology of the jejunum in TM broiler chicks. The $\mathrm{VH}, \mathrm{VW}, \mathrm{VSA}$, and CD did not significantly differ between the control, TML and TMH groups under the different conditions. However, the VH: CD ratio was significantly lower in the TMH group than in the control group under HS conditions $(\mathrm{p}<0.05)$.

\section{Discussion}

TM by elevating or decreasing the incubation temperature of broiler eggs is postulated to be an important strategy to improve post-hatch thermotolerance acquisition. However, such embryonic
TM should be applied during the critical period of hypothalamic-pituitary-thyroid and hypothalamic-pituitary-adrenal axes development [43,44]. TM is used to change the "setpoint" of the systems regulating thermoregulation during the development and maturation of the thermoregulatory center in the brain (e.g., days 6-16 of incubation) [45]. The aim of the current study was to examine the influence of embryonic TM on ileum mRNA levels of junctional proteins (CLDN1, CLDN5, OCLN, and CDH1), heat shock proteins (HSP70 and HSP90), HSF (HSF1 and $H S F 3$ ), and immune response genes (IL6, IL8, TLR2, and TLR4) as well as on the histological morphometrics of the jejunum and ileum during post-hatch exposure to heat and CSs.

Impact of TML and TMH temperatures on the physiological parameters of broilers subjected to thermal stress

TMH accelerated the hatchability rate compared with the control group, while the TML group had an insignificant delaying effect on the hatchability. The previous studies reported contradictory findings on the overall hatchability rate, which may be attributed to the use of broilers of different strains types, ages, or incubation temperatures and relative humidities [46-49]. Formerly, a low incubation temperature was found to extend the incubation period of broiler eggs and subsequently delayed hatching [50,51]. 
Table-3: Effects of heat and cold exposures for 4 days (post-hatch days 21-25) on the morphology of ileum in broiler chickens subjected to thermal manipulation (TM) during embryogenesis $(n=3)$.

\begin{tabular}{lllllll}
\hline Day 4 of stress & \multicolumn{5}{c}{ Ileum } \\
\cline { 3 - 7 } & & \multicolumn{1}{c}{ VH $(\boldsymbol{\mu} \mathbf{m})$} & \multicolumn{1}{c}{$\mathbf{V W}(\boldsymbol{\mu m})$} & \multicolumn{1}{c}{ VSA $\left(\boldsymbol{\mu m ^ { 2 }}\right)$} & CD $(\boldsymbol{\mu m})$ & VH:CD $(\boldsymbol{\mu m})$ \\
\hline TN & Control & $600.61 \pm 27.43$ & $154.67 \pm 7.31$ & $292758 \pm 25479$ & $142.99 \pm 3.79$ & $4.2 \pm 0.16$ \\
& TML & $649.13 \pm 16.34$ & $137.81 \pm 16.79$ & $282610 \pm 41917$ & $156.58 \pm 7.82$ & $4.17 \pm 0.26$ \\
& TMH & $662.73 \pm 104.83$ & $135.08 \pm 11.57$ & $274235 \pm 21247$ & $151.18 \pm 17.27$ & $4.34 \pm 0.19$ \\
CHS & Control & $594.75 \pm 42.37$ & $137.4 \pm 13.16$ & $260095 \pm 44391$ & $180.99 \pm 19.41$ & $3.42 \pm 0.63$ \\
& TML & $632.01 \pm 60.31$ & $157.99 \pm 15.27$ & $319131 \pm 57304$ & $134.39 \pm 11.57$ & $4.82 \pm 0.79$ \\
& TMH & $646.22 \pm 40.6$ & $142.74 \pm 12.6$ & $291838 \pm 39722$ & $144.07 \pm 18.02$ & $4.61 \pm 0.59$ \\
CCS & Control & $720.44 \pm 63.96$ & $125.42 \pm 7.15$ & $286560 \pm 409180$ & $167.66 \pm 26.82$ & $4.45 \pm 0.54$ \\
& TML & $656.95 \pm 86.62$ & $173.02 \pm 37.31$ & $361795 \pm 108242$ & $170.26 \pm 25.56$ & $3.92 \pm 0.46$ \\
& TMH & $892.48 \pm 205.18$ & $120.04 \pm 3.02$ & $333993 \pm 71003$ & $163.72 \pm 3.38$ & $5.44 \pm 1.21$ \\
\hline
\end{tabular}

TN: thermal neutral. CHS: chronic heat stress. CCS: chronic cold stress. VH: villus height. VW: villus width. VSA: villus surface area. CD: crypt depth. $\mathrm{VH}: \mathrm{CD}$ : villus height to crypt depth ratio

Table-4: Effect of heat and cold exposures for 4 days (post-hatch days 21-25) on the morphology of jejunum in broiler chickens subjected to thermal manipulation (TM) during embryogenesis $(n=3)$.

\begin{tabular}{|c|c|c|c|c|c|c|}
\hline \multicolumn{2}{|c|}{ Day 4 of stress } & \multicolumn{5}{|c|}{ Jejunum } \\
\hline & & VH $(\mu \mathrm{m})$ & VW $(\mu \mathrm{m})$ & VSA $\left(\mu m^{2}\right)$ & CD $(\mu \mathrm{m})$ & VH:CD $(\mu \mathrm{m})$ \\
\hline \multirow[t]{3}{*}{$\mathrm{TN}$} & Control & $835.41 \pm 24.03^{a}$ & $153.66 \pm 7.13$ & $403212 \pm 22679.3^{a}$ & $148.72 \pm 8.37^{\mathrm{ac}}$ & $5.65 \pm 0.3^{\mathrm{ac}}$ \\
\hline & TML & $800.59 \pm 43.99^{a}$ & $140.32 \pm 18.18$ & $352530 \pm 46415^{a}$ & $173.25 \pm 8.02^{\mathrm{abc}}$ & $4.63 \pm 0.21^{a}$ \\
\hline & $\mathrm{TMH}$ & $971.91 \pm 40.86^{\mathrm{ac}}$ & $135.24 \pm 2.87$ & $413384 \pm 25910^{a}$ & $192.64 \pm 29.63^{\mathrm{abc}}$ & $5.28 \pm 0.78^{\mathrm{a}}$ \\
\hline \multirow[t]{3}{*}{$\mathrm{CHS}$} & Control & $888.19 \pm 59.23^{\mathrm{ac}}$ & $147.3 \pm 1.4$ & $411339 \pm 31237^{a}$ & $202.1 \pm 7.75^{\mathrm{abc}}$ & $4.39 \pm 0.13^{a}$ \\
\hline & TML & $832.8 \pm 46.03^{a c}$ & $153.91 \pm 19.74$ & $397870 \pm 34897^{a}$ & $228 \pm 29.01^{\mathrm{ab}}$ & $3.73 \pm 0.32^{\mathrm{a}}$ \\
\hline & $\mathrm{TMH}$ & $1111 \pm 76.38^{\mathrm{bc}}$ & $145.78 \pm 18.89$ & $500007 \pm 38234^{\mathrm{ac}}$ & $205.46 \pm 11.27^{\mathrm{abc}}$ & $5.4 \pm 0.08^{a}$ \\
\hline \multirow[t]{3}{*}{ CCS } & Control & $1115.71 \pm 54.7^{\mathrm{bc}}$ & $170.36 \pm 22.87$ & $604126 \pm 111257^{a b}$ & $240.31 \pm 10.33^{b}$ & $4.66 \pm 0.33^{a}$ \\
\hline & TML & $1305.68 \pm 86.43^{b}$ & $198.41 \pm 6.19$ & $812706 \pm 55858^{b}$ & $166.17 \pm 15.25^{\mathrm{abc}}$ & $8.03 \pm 1.04^{b c}$ \\
\hline & $\mathrm{TMH}$ & $1270.03 \pm 6.04^{b}$ & $175.36 \pm 10.74$ & $699161 \pm 41537^{\mathrm{bc}}$ & $137.41 \pm 1.69^{c}$ & $9.25 \pm 0.15^{b}$ \\
\hline
\end{tabular}

TN: thermal neutral. CHS: chronic heat stress. CCS: chronic cold stress. VH: villus height. VW: villus width. VSA: villus surface area. CD: crypt depth. $\mathrm{VH}: \mathrm{CD}$ : villus height to crypt depth ratio.

${ }^{a-c}$ within the same column, means \pm SEM with different superscripts are significantly different $(p<0.05)$

Table-5: Effects of heat and cold exposures for 7 days (post-hatch days 21-28) on the morphology of ileum in broiler chickens subjected to thermal manipulation (TM) during embryogenesis $(n=3)$.

\begin{tabular}{llccccc}
\hline Day 7 of stress & \multicolumn{5}{c}{ Ileum } \\
\cline { 2 - 7 } & & $\mathbf{V H}(\boldsymbol{\mu m})$ & $\mathbf{V W}(\boldsymbol{\mu m})$ & $\mathbf{V S A}\left(\boldsymbol{\mu m ^ { 2 } )}\right.$ & $\mathbf{C D}(\boldsymbol{\mu m})$ & VH:CD $(\boldsymbol{\mu m})$ \\
\hline TN & Control & $589.46 \pm 34.83^{\mathrm{ab}}$ & $154.66 \pm 19.49$ & $286448 \pm 39650$ & $165.85 \pm 8.22^{\mathrm{a}}$ & $3.59 \pm 0.38^{\mathrm{a}}$ \\
& TML & $623.96 \pm 24.58^{\mathrm{ab}}$ & $160.99 \pm 8.96$ & $316767 \pm 29997$ & $160.51 \pm 2.71^{\mathrm{a}}$ & $3.89 \pm 0.13^{\mathrm{ac}}$ \\
& TMH & $702.51 \pm 28.51^{\mathrm{a}}$ & $153.15 \pm 10.35$ & $338045 \pm 27402$ & $146.57 \pm 4.34^{\mathrm{ab}}$ & $4.8 \pm 0.27^{\mathrm{abc}}$ \\
$\mathrm{CHS}$ & Control & $612.83 \pm 12.7^{\mathrm{ab}}$ & $146.54 \pm 18.22$ & $283321 \pm 40641$ & $102.9 \pm 1.15^{\mathrm{b}}$ & $5.96 \pm 0.13^{\mathrm{b}}$ \\
& TML & $579.02 \pm 17.23^{\mathrm{b}}$ & $128.86 \pm 3.59$ & $234214 \pm 8768$ & $130.73 \pm 19.85^{\mathrm{ab}}$ & $4.61 \pm 0.61^{\mathrm{ab}}$ \\
& TMH & $700.37 \pm 12.19^{\mathrm{a}}$ & $146.03 \pm 8.62$ & $321582 \pm 23228$ & $133.75 \pm 11.95^{\mathrm{ab}}$ & $5.3 \pm 0.37^{\mathrm{bc}}$ \\
$\mathrm{CCS}$ & Control & $605.37 \pm 26.47^{\mathrm{ab}}$ & $162.35 \pm 12.57$ & $309887 \pm 34408$ & $113.75 \pm 6.92^{\mathrm{b}}$ & $5.33 \pm 0.11^{\mathrm{bc}}$ \\
& TML & $634.12 \pm 19.87^{\mathrm{ab}}$ & $154.34 \pm 15.22$ & $306636 \pm 28696$ & $151.83 \pm 3.84^{\mathrm{b}}$ & $4.18 \pm 0.18^{\mathrm{ac}}$ \\
& TMH & $704.88 \pm 16.89^{\mathrm{a}}$ & $162.3 \pm 8.13$ & $360044 \pm 26628$ & $142.67 \pm 11.7^{\mathrm{ab}}$ & $4.99 \pm 0.34^{\mathrm{ab}}$ \\
\hline
\end{tabular}

TN: thermal neutral. CHS: chronic heat stress. CCS: chronic cold stress. VH: villus height. VW: villus width. VSA: villus surface area. CD: crypt depth. VH:CD: villus height to crypt depth ratio.

a-c within the same column, means \pm SEM with different superscripts are significantly different $(p<0.05)$.

This extended incubation period occurred due to the slowing down of the metabolism (hypometabolism), mainly of lipids and carbohydrates [51]. On a similar note, it was shown previously that a high incubation temperature shortens the incubation period due to the increased metabolism [52-55].

The present study showed that TML led to significantly decreased BWs during the early posthatch life, but no significant difference in the BWs was observed during the $5^{\text {th }}$ week of the post-hatch life. Except for day 7 of CHS, there was significant reduction in the BW of the stressed-TMH groups compared to TN-TMH groups on day 1 and 4 of CHS $(p<0.05)$. Similarly, during CCS, except for day 1 and day 4 , there was significant increase in the BW of the stressed-TMH groups compared to TN-TMH groups after 7 days of $\operatorname{CCS}(p<0.05)$.

Previously, conflicting results were found for BWs in the early post-hatch life, since different studies reported that TM increased, reduced, or had no impact on hatchling weights [56-59]. The decreased BW during early post-hatch life in TML chicks is 
Table-6. Effects of heat and cold exposures for 7 days (post-hatch days 21-28) on the morphology of jejunum in broiler chickens subjected to thermal manipulation (TM) during embryogenesis $(n=3)$.

\begin{tabular}{|c|c|c|c|c|c|c|}
\hline \multicolumn{2}{|c|}{ Day 7 of stress } & \multicolumn{5}{|c|}{ Jejunum } \\
\hline & & VH $(\mu \mathrm{m})$ & VW $(\mu \mathrm{m})$ & VSA $\left(\mu m^{2}\right)$ & $C D(\mu \mathrm{m})$ & VH:CD $(\mu \mathrm{m})$ \\
\hline \multirow[t]{3}{*}{$\mathrm{TN}$} & Control & $826.93 \pm 46.84$ & $154.22 \pm 17.19$ & $395423 \pm 20616$ & $144.5 \pm 17.69$ & $5.95 \pm 0.94^{\mathrm{ab}}$ \\
\hline & TML & $809.49 \pm 72.79$ & $153.6 \pm 2.39$ & $390563 \pm 36146$ & $167.74 \pm 15.92$ & $4.84 \pm 0.18^{a}$ \\
\hline & $\mathrm{TMH}$ & $972.88 \pm 55.1$ & $152.7 \pm 15.39$ & $470638 \pm 66996$ & $186.53 \pm 19.45$ & $5.3 \pm 0.46^{a}$ \\
\hline \multirow[t]{3}{*}{$\mathrm{CHS}$} & Control & $1077.55 \pm 179.38$ & $127.55 \pm 11.57$ & $431846 \pm 85276$ & $124.89 \pm 19.57$ & $8.6 \pm 0.19^{b}$ \\
\hline & TML & $818.61 \pm 21.61$ & $145.4 \pm 10.59$ & $373906 \pm 29725$ & $152.05 \pm 15.43$ & $5.51 \pm 0.63^{\mathrm{ab}}$ \\
\hline & $\mathrm{TMH}$ & $912.91 \pm 186.41$ & $149.94 \pm 8.37$ & $431528 \pm 95771$ & $174.2 \pm 34.75$ & $5.29 \pm 0.82^{a}$ \\
\hline \multirow[t]{3}{*}{ CCS } & Control & $999.37 \pm 131.72$ & $147.4 \pm 14.26$ & $451968 \pm 27685$ & $177.68 \pm 28.22$ & $5.75 \pm 0.6^{\mathrm{ab}}$ \\
\hline & $\mathrm{TML}$ & $1043.09 \pm 105.68$ & $148.26 \pm 24.49$ & $470046 \pm 35167$ & $195.93 \pm 10.14$ & $5.41 \pm 0.85^{\mathrm{ab}}$ \\
\hline & $\mathrm{TMH}$ & $1000.27 \pm 20.17$ & $146.97 \pm 12.12$ & $460470 \pm 30553$ & $146.33 \pm 1.78$ & $6.84 \pm 0.1^{\mathrm{ab}}$ \\
\hline
\end{tabular}

TN: thermal neutral. CHS: chronic heat stress. CCS: chronic cold stress. VH: villus height. VW: villus width. VSA: villus surface area. CD: crypt depth. $\mathrm{VH}: \mathrm{CD}$ : villus height to crypt depth ratio.

$a, b$ within the same column, means \pm SEM with different superscripts are significantly different $(p<0.05)$

mostly associated with the decreased metabolic rate, since a lower metabolic rate could lead to delayed and retarded growth as energy is diverted toward maintenance of existing tissues rather than growth [50]. However, it had been reported that a low incubation temperature led to significantly increased BW during post-hatch life [60]. In the current study, TMH led to significantly higher BW especially in the $5^{\text {th }}$ week post-hatch. Consistently, it had been reported that eggs incubation at $38.5^{\circ} \mathrm{C}$ on embryonic days $16-18$ and at $39^{\circ} \mathrm{C} 18 \mathrm{~h} / \mathrm{d}$ on embryonic days $12-18$ led to increased broiler $\mathrm{BW}$, however, eggs incubation at $39.5^{\circ} \mathrm{C}$ for $3 \mathrm{~h} / \mathrm{d}$ during ED 8-10 did not significantly affect poultry BW during post-hatch life $[49,61]$. Previously, it had been shown that eggs incubation at $39.5^{\circ} \mathrm{C}$ for $12 \mathrm{~h} / \mathrm{d}$ on embryonic days 7-16 increased myofiber diameters and improved muscle growth in comparison with controls until post-hatch day 35 [62]. In addition, the cyclic increased incubation of broiler temperature of broiler eggs was reported to increase pectoral muscle mass and increased myoblast proliferation during their post-hatch lives [49,63-65].

No major $T^{b}$ changes were observed at all stages of development, except for the post-hatch days 1, 7, 14 , and 21. Similarly, it has been reported that $\mathrm{T}^{\mathrm{b}}$ of TM chicks $\left(38.8^{\circ} \mathrm{C}\right.$ for 6 or $\left.18 \mathrm{~h}\right)$ did not differ significantly from that of the controls $[37,49]$. In the contrary, Loyau et al. [66] reported previously that the $\mathrm{T}^{\mathrm{b}}$ of $\mathrm{TM}$ chicks were significantly lower $\left(39.5^{\circ} \mathrm{C}\right.$ for $12 \mathrm{~h}$ during ED 7-16) than those of the controls at hatching and until day 28 of age. Moreover, the previous studies have also reported that TM $\left(39.5^{\circ} \mathrm{C}\right.$ for $12 \mathrm{~h} / \mathrm{d}$ during ED 7-16) had a long-lasting effect on thermotolerance acquisition of broilers that persisted until an early marketing age (day 35 of age) [62,67-69]. Those results showed that selected TM conditions have not improved the long-term thermotolerance acquisition in chicks following TM.

Interestingly, the present study shows that the $\mathrm{T}^{\mathrm{b}}$ of the TM chicks was significantly lower than that of the controls after 1, 4, and 7 days of CHS compared to those of the controls. Our results indicate that $\mathrm{TM}$ improves thermotolerance acquisition in TM chicks. Previously, it has been reported that the $\mathrm{T}^{\mathrm{b}}$ of TM chicks was significantly lower than that of controls [56,66,70]. On the other hand, Collin et al. reported significant hyperthermia in TM and control chicks following HS on post-hatch day 42, with higher mortality rates in TM chicks [50]. These results indicate that the TM conditions tested by Collin et al. [49] failed to improve long-term thermotolerance acquisition in TM chicks. Furthermore, the previous studies have also reported that TM $\left(39.5^{\circ} \mathrm{C}\right.$ for $12 \mathrm{~h} / \mathrm{d}$ during ED 7-16) had a long-lasting effect on thermotolerance acquisition by broilers that persisted until an early marketing age (day 35 of age) $[62,67,68]$. This suggested that TM during broiler chicken embryogenesis may improve thermotolerance acquisition in chickens raised in regions with high ambient temperatures, with a potentially significant improvement in economic return.

\section{Impact of TML and TMH temperatures on the expres- sion of junctional and heat shock genes in broilers subjected to thermal stress}

Thermal stress (both heat and cold) is one of the serious physical factors that impair the intestinal barrier. The significant damage to the intestinal epithelia is a major cause of the mortality associated with thermal stress [71-75]. Under thermal stress, the body shifts the thermoregulatory mechanisms away from the viscera and toward the peripheral circulation to assist in heat dissipation, which results in visceral ischemia and subsequent hypoxia. Hypoxic conditions in the gastrointestinal tract, which is part of the viscera, lead to epithelial deterioration and dysfunction of junctional proteins in the intestinal barrier [76]. The intestinal barrier is composed of both adherents and tight junctions, and it possesses a critical role in nutrient, water, and electrolyte absorption as well as in the protection of the gastrointestinal tract from pathogenic invasions [77-79].

The tight junction proteins, CLDN and OCLN, comprise the apical-most junction of a series of cellular contacts that build lateral connections between 
neighboring cells [80,81]. Any damage in the intestinal junctional proteins increases the permeability to the luminal antigens and pathogens translocation, resulting in endogenous infection and eventually endotoxemia, and impairs the absorption of nutrients [11,12].

The present study illustrated that HS increased $C L D N 1$ and CLDN5 expression in the control and $\mathrm{TMH}$ groups compared to their TN counterparts. CS also significantly increased CLDN1 and CLDN5 expression in the TMH subgroup, but neither heat nor CS affected the expression of these genes in the TML subgroup. In contrast, heat and CS did not significantly change the expression of the OCLN and $C D H 1$ genes in any of the subgroups. Moreover, the expression of all evaluated junctional proteins was significantly lower in the TML subgroup compared with the control subgroups under thermal stress exposure.

Corresponding with our findings, it was found that thermal exposure increases the expression of CLDN1 [14-16], OCLN [16], CDH1, and CLDN5 [14]. These findings suggest that upregulation in gene expression is a compensatory response to the damaged junctional proteins or to the rupture of the intestinal epithelia. However, such a compensatory response was not observed in the TML subgroup as this subgroup possessed comparable mRNA levels of junctional proteins under all tested conditions, suggesting that this subgroup was less affected by thermal stress. Previously, it was found that continuous TM from embryonic day 11 until hatching day improved the overall intestinal morphology after post-hatch exposure to artificial infection with $S$. Enteritidis [42].

In the present study, thermal stress significantly upregulated HSF $1, H S F 3, H S P 70$, and HSP90 expression in the control group. Similar findings were observed in the TMH subgroup (except for HSP90), but the expression of these upregulated genes was significantly lower than that in the control subgroup. In contrast, for the TML subgroup, HS only increased HSF 1 expression and CS did not change the expression of any of the investigated heat shock genes.

In accordance with our findings, TM has been found to have a long-lasting effect on HSF1, HSF3, and HSP70 expression, which was linked to improved acquisition of heat tolerance in broilers $[35,37,70,82]$. Such alterations in expression dynamics may be the result of epigenetic changes triggered by TM, as TM was previously found to affect DNA methylation of the HSP70 promoter region which subsequently altered its expression during post-hatch life [83]. Similarly, it was shown that chicks subjected to TM resulted had decreased HSF $1, H S F 3$, and HSP70 expression in the jejunal mucosa after 7 days of HS exposure in comparison with chicks incubated under standard conditions [40]. Furthermore, CS was reported to induce the expression of HSF 3 and $H S P 70$ in the liver and spleen of broiler chickens after 5 days of exposure to CS, but TM mitigated this response [84]. During thermal stress, the decreased expression of heat shock proteins in TM chicks compared to controls suggests that TM chicks were less susceptible to thermal stress.

It could be concluded that the heat-induced expression of HSP70 in the control chicks might be associated with $O C L N$ expression. It was previously found that inhibiting HSP expression prevented an upregulation in $O C L N$ expression in vitro, which led to a serious disturbance in the junctional localization of the OCLN protein during HS and resulted in high permeability of the tight junctions [85]. The current results show that, under TN conditions, TML chicks had significantly higher $H S P 70$ expression compared to controls. Previously, it was found that induction of HSP70 was associated with acquired thermotolerance in different cell types [86].

\section{Impact of TML and TMH temperatures on the expres- sion of inflammatory genes in broilers subjected to thermal stress}

Deteriorated integrity of the tight junctions and intestinal barrier increases the paracellular permeability to luminal pathogens and toxic material, allowing them to move from the lumen and into the bloodstream [87]. This may result in an inflammatory response when these toxins or pathogens bind to TLRs (namely, TLR2 and TLR4) and activate the signaling pathways, thereby inducing pro-inflammatory cytokines such as IL6 and IL8 [88-90]. IL6 and IL8 are pro-inflammatory cytokines with critical roles in innate immunity and the induction of the acute phase response [91,92]. IL6 is a key regulator of both systematic and local acute inflammation primarily by modulating pro-inflammatory cytokine levels [93]. Several studies have found that acute HS causes an increase in IL6 levels, which then triggers tissue protection mechanisms [82,94-97]. IL6 promotes tissue repair by activating the IL 8 cytokine, which plays an important role in wound healing $[92,98,99]$. In fact, it has been hypothesized that, during acute HS, IL6, and its related pathways play a critical role in regulating the mechanisms that protect against tissue disruption in broiler chicken small yellow follicles [100].

$I L-6$ acts as a heat-shock gene in chickens, being activated by $H S F 3$ during HS. Such regulation is required because increased $I L-6$ expression in chicken yellow follicles in response to AHS has been linked to the regulation of protective pathway [101]. $I L-6$ is required for tissue protection, healing, and regeneration in response to stress or tissue injury [102-104]. Indeed, pre-treatment with $I L-6$ has been shown to have a protective effect during AHS exposure in mice by regulating physiological responses, resulting in tissue damage shielding [94]. This suggests that TM boosted the immune-protective response by increasing $I L-6$ expression during HS. The previous studies reported that HS induces TLR4, IL6, and IL8 expression in the small intestines of both chickens and mammals $[14,95,105]$. Furthermore, corticosterone-induced stress led to upregulated IL 6 and IL8 expression in chickens [106,107]. 
In this study, thermal stress led to upregulation expression of $I L-6, I L-8, T L R 2$, and TLR4 in control incubation-group, and upregulated $I L-6, I L-8$, and TLR4 in TMH subgroup in comparison with their TN counterparts. However, TLR4 expression was significantly lower in TMH compared to control group during heat exposure. In TML incubation-group, the expression of $I L-6, T L R 2$, and TLR4 under thermal stress was comparable to that under TN condition, and their expression in TML was significantly lower than that in control group exposed to thermal stress. However, $I L-8$ expression in TML was increased only under cold exposure. The upregulation of the aforementioned immune response genes might be triggered by the invasion of Gram-negative bacteria as a result of disrupted intestinal barrier [108], or by to the direct effect of the HS, since TLR4 has been considered as a stress-related biosensor [109]. In addition, TLR-4 activation can lead to intestinal barrier damage, since it was reported that TLR-4 knockout mice were protected from intestinal hyperpermeability induced by burn [90]. The downregulated expression of immune response genes in TM chicks may indicate that the barrier damage in the ileum under thermal stress was attenuated in comparison with the control. Similarly, it was reported previously that HS led to the divergent expression of TLR2,TLR4, and other pro-inflammatory cytokines in the jejunum of TM chicks and chicks incubated under standard conditions [40].

TLRs are pathogen-recognition receptors, meaning they can recognize pathogen-associated signals as well as danger-associated molecular patterns (DAMPs) [110]. HSP70, a DAMP that is secreted by various cells during stress and binds to TLR2 and TLR4, is one example $[111,112]$. The interaction of $H S P 70$ with TLR2 and TLR4 activates signal transduction cascades, which results in the activation of NF-B, which induces the expression of $I L-6$ [111]. This points to a third mechanism for $I L-6$ induction by DAMPs during HS: the activation of healing responses. Overall, the current findings suggest that TM improves broiler resistance to AHS by promoting tissue healing, regeneration, and protective immune responses characterized by the induction of $I L-6$ expression and the components of its production pathways.

\section{Impact of TML and TMH temperatures on the histo- morphology of the small intestine in broilers sub- jected to thermal stress}

The major site of nutrient digestion and absorption in broilers is the small intestine, where the VH and VSA are important indicators of this intestinal function. Moreover, $\mathrm{CD}$ and the $\mathrm{VH}$ : $\mathrm{CD}$ ratio are especially important indicators of the cellular turnover at the villous surface. It was previously reported that longer villi and greater villous surface area suggest an enhanced nutrient absorption capability [113-115]. If the $\mathrm{CD}$ is deeper, this might indicate a rapid metabolism to maintain the intestinal villi renewal $[113,115]$. Any shortening in the $\mathrm{VH}$ or $\mathrm{CD}$ could result in a decreased nutrients absorption capability of the intestine $[114,116]$.

The present study shows that thermal stress did not lead to significant histomorphometric changes in the ileum of TML and TMH chicks. However, in the control group, 7 days of thermal stress significantly increased the $\mathrm{CD}$ and decreased the $\mathrm{VH}$ : $\mathrm{CD}$ ratio in the ileum. Furthermore, heat exposure did not lead to significant histomorphometric changes in the jejunum of the different subgroups, while 4 days of CS led to significantly increased $\mathrm{VH}, \mathrm{VSA}$, and $\mathrm{VH}$ : CD ratio in the jejunum of both the TML and TMH groups, but it significantly increased the $\mathrm{VH}$ and $\mathrm{CD}$ in the control group. However, the TML and TMH subgroups had significantly increased $\mathrm{VH}$ : CD ratio compared to the control group after 4 days of CS.

In contrast, the previous studies reported a significant decrease in the $\mathrm{VH}$ and an increase in $\mathrm{CD}$ as a response to thermal stress, suggesting that thermal stress led to significant damage to the mucosal layer and the increased $\mathrm{CD}$ is a normal response to the renewal of the villi epithelia [21,23,24,117]. However, these studies were conducted with more extreme cold or heat exposure experiments in terms of temperature (the cold exposures were below $8^{\circ} \mathrm{C}$ ) and duration (acute and prolonged/chronic exposures). On the other hand, early life cold acclimation and embryonic cold stimulation were found to enhance the metabolism and to improve the growth of the intestinal epithelia, which eventually led to increased $\mathrm{VH}[19,24,118]$. In addition, continuous TM from embryonic day 11 until hatching day decreased the severity of post-hatch $S$. Enteritidis infection in the small intestine, since TM chicks possessed increased $\mathrm{VH}$ in the ileum and improved overall intestinal morphology [42]. Correspondingly, the results of the present study show that TM chicks had a higher $\mathrm{VH}$ : CD ratio compared to the control group after CS exposure.

\section{Conclusion}

The present findings suggest that embryonic TM alleviated the impact of post-hatch thermal stress on the epithelial junctional barrier integrity and inflammatory response in the small intestine of broiler chickens. Furthermore, the current results may indicate that embryonic TM may alter the small intestine's absorptive capability in broilers during post-hatch thermal stress exposure by increasing the $\mathrm{VH}$ and the $\mathrm{CD}$. One limitation of the present study is that it had taken into consideration the mRNA transcription of genes but not the actual protein levels of junctional proteins. Moreover, further research is needed to understand the effect of more prolonged exposure to thermal stress and more extreme temperatures on the intestinal integrity of TM chicks.

\section{Authors' Contributions}

MBA: Funding acquisition and project administration. KEK and KMMS: Collection of the samples. KEK and KMMS: Data collection and analysis. 
MBA: Analyzed the data. All authors shared in writing of this manuscript and revised it. All authors read and approved the final manuscript.

\section{Acknowledgments}

The authors would like to express their deep appreciation and thanks to the Deanship of Research, Jordan University of Science and Technology for its financial support of this work (Grant\#: 395/2019). The authors would also like to thank Miss Amneh Tarkhan for her excellent technical assistance and valuable comments.

\section{Competing Interests} interests.

The authors declare that they have no competing

\section{Publisher's Note}

Veterinary World remains neutral with regard to jurisdictional claims in published institutional affiliation.

\section{References}

1. Pawar, S., Sajjanar, B., Lonkar, V., Nitin, K., Kadam, A., Nirmale, A., Brahmane, M. and Bal, S. (2016) Assessing and mitigating the impact of heat stress in poultry. $A d v$. Anim. Vet. Sci., 4(6): 332-341.

2. Ren, T. and Xin, C.A. (1997) The influence of cold stress on the chicken. Poult. Husbandry Dis. Control, 2: 32-33.

3. Lara, L.J. and Rostagno, M.H. (2013) Impact of heat stress on poultry production. Animals, 3(2): 356-369.

4. Olanrewaju, H., Purswell, J., Collier, S. and Branton, S. (2010) Effect of ambient temperature and light intensity on physiological reactions of heavy broiler chickens. Poult. Sci., 89(12): 2668-2677.

5. Arjona, A.A., Denbow, D.M. and Weaver, W.D. Jr. (1988) Effect of heat stress early in life on mortality of broilers exposed to high environmental temperatures just prior to marketing. Poult. Sci., 67(2): 226-231

6. Sahin, E. and Gumuslu, S. (2004) Cold-stress-induced modulation of antioxidant defence: Role of stressed conditions in tissue injury followed by protein oxidation and lipid peroxidation. Int. J. Biometeorol., 48(4): 165-171.

7. Smith, M. and Teeter, R. (1993) Effects of feed intake and environmental temperature on chick growth and development. J. Agric. Sci., 121(3): 421-426.

8. Nardone, A., Ronchi, B., Lacetera, N., Ranieri, M.S. and Bernabucci, U. (2010) Effects of climate changes on animal production and sustainability of livestock systems. Livest. Sci., 130(1): 57-69.

9. Elphick, D. and Mahida, Y. (2005) Paneth cells: Their role in innate immunity and inflammatory disease. Gut, 54(12): 1802-1809.

10. Song, B., Li, H., Wu, Y., Zhen, W., Wang, Z., Xia, Z. and Guo, Y. (2017) Effect of microencapsulated sodium butyrate dietary supplementation on growth performance and intestinal barrier function of broiler chickens infected with necrotic enteritis. Anim. Feed Sci. Technol., 232(6): 6-15.

11. Berkes, J., Viswanathan, V., Savkovic, S. and Hecht, G. (2003) Intestinal epithelial responses to enteric pathogens: effects on the tight junction barrier, ion transport, and inflammation. Gut, 52(3): 439-451.

12. Ulluwishewa, D., Anderson, R.C., McNabb, W.C., Moughan, P.J., Wells, J.M. and Roy, N.C. (2011) Regulation of tight junction permeability by intestinal bacteria and dietary components. J. Nutr., 141(5): 769-776.

13. Cheng, Y., Chen, Y., Chen, R., Su, Y., Zhang, R., He, Q.,
Wang, K., Wen, C. and Zhou, Y. (2019) Dietary mannan oligosaccharide ameliorates cyclic heat stress-induced damages on intestinal oxidative status and barrier integrity of broilers. Poult. Sci., 98(10): 4767-4776.

14. Varasteh, S., Braber, S., Akbari, P., Garssen, J. and FinkGremmels, J. (2015) Differences in susceptibility to heat stress along the chicken intestine and the protective effects of galacto-oligosaccharides. PLoS One, 10(9): e0138975.

15. Santos, R.R., Awati, A., Roubos-van den Hil, P.J., van Kempen, T.A., Tersteeg-Zijderveld, M.H., Koolmees, P.A., Smits, C. and Fink-Gremmels, J. (2019) Effects of a feed additive blend on broilers challenged with heat stress. Avian Pathol., 48(6): 582-601.

16. Del Vesco, A.P., de Souza Khatlab, A., Santana, T.P., Pozza, P.C., Soares, M.A.M., Brito, C.O., Barbosa, L.T. and Gasparino, E. (2020) Heat stress effect on the intestinal epithelial function of broilers fed methionine supplementation. Livest. Sci., 240: 104152

17. Fu, J., Liu, C.P., Zhang, Z.W., Xing, M.W. and Xu, S.W. (2013) Influence of inflammatory pathway markers on oxidative stress induced by cold stress in intestine of quails. Res. Vet. Sci., 95(2): 495-501.

18. Quinteiro-Filho, W., Ribeiro, A., Ferraz-de-Paula, V., Pinheiro, M., Sakai, M., Sá, L., Ferreira, A. and PalermoNeto, J. (2010) Heat stress impairs performance parameters, induces intestinal injury, and decreases macrophage activity in broiler chickens. Poult. Sci., 89(9): 1905-1914.

19. Shinder, D., Ruzal, M., Giloh, M., Druyan, S., Piestun, Y. and Yahav, S. (2011) Improvement of cold resistance and performance of broilers by acute cold exposure during late embryogenesis. Poult. Sci., 90(3): 633-641.

20. Zhao, F.Q., Zhang, Z.W., Yao, H.D., Wang, L.L., Liu, T., Yu, X.Y., Li, S. and Xu, S.W. (2013) Effects of cold stress on mRNA expression of immunoglobulin and cytokine in the small intestine of broilers. Res. Vet. Sci., 95(1): 146-155.

21. He, X., Lu, Z., Ma, B., Zhang, L., Li, J., Jiang, Y., Zhou, G. and Gao, F. (2018) Effects of chronic heat exposure on growth performance, intestinal epithelial histology, appetite-related hormones and genes expression in broilers. J. Sci. Food Agric., 98(12): 4471-4478.

22. Song, J., Xiao, K., Ke, Y., Jiao, L., Hu, C., Diao, Q., Shi, B. and Zou, X. (2014) Effect of a probiotic mixture on intestinal microflora, morphology, and barrier integrity of broilers subjected to heat stress. Poult. Sci., 93(3): 581-588.

23. Ashraf, S., Zaneb, H., Masood, S., Yousaf, S., Usman, M., Rehman, H., Sikandar, A., Shah, M. and Rehman, H. (2020) Growth performance, hormonal dynamics and intestinal microarchitecture in broilers fed $\beta$-galacto-oligosaccharides during cyclic cold stress. J. Anim. Plant Sci., 30(2): 288-297.

24. Qureshi, S., Khan, H., Amin, U., Mir, M., Adil, S. and Sofi, A. (2020) Influence of cold stress and its remedial measures on jejunal Histomorhology of broiler chicken. J. Pharm. Innov., 9(7): 225-229.

25. Garriga, C., Hunter, R.R., Amat, C., Planas, J.M., Mitchell, M.A. and Moretó, M. (2006) Heat stress increases apical glucose transport in the chicken jejunum. Am. $J$. Physiol. Regul. Integr. Comp. Physiol., 290(1): 195-201.

26. Parsell, D. and Lindquist, S. (1993) The function of heatshock proteins in stress tolerance: Degradation and reactivation of damaged proteins. Annu. Rev. Genet., 27(1): 437-496.

27. Akerfelt, M., Morimoto, R.I. and Sistonen, L. (2010) Heat shock factors: Integrators of cell stress, development and lifespan. Nat. Rev. Mol. Cell Biol., 11(8): 545-555.

28. Fujimoto, M. and Nakai, A. (2010) The heat shock factor family and adaptation to proteotoxic stress. FEBS J., 277(20): 4112-4125.

29. Song, D.J. and King, A.J. (2015) Effects of heat stress on broiler meat quality. Worlds Poult. Sci. J., 71(4): 701-709.

30. Fulda, S., Gorman, A.M., Hori, O. and Samali, A. (2010) Cellular stress responses: Cell survival and cell death. Int. J. Cell Biol., 2010: 214074. 
31. Varasteh, S., Braber, S., Akbari, P., Garssen, J.J. and FinkGremmels, J. (2015) Differences in susceptibility to heat stress along the chicken intestine and the protective effects of galacto-oligosaccharides. PLoS One, 10(9): e0138975.

32. Joly, A.L., Wettstein, G., Mignot, G., Ghiringhelli, F. and Garrido, C. (2010) Dual role of heat shock proteins as regulators of apoptosis and innate immunity. J. Innate Immun., 2(3): 238-247.

33. Morita, V.S., Almeida, V.R., Matos, J.B. Jr., Vicentini, T.I., van den Brand, H. and Boleli, I.C. (2016) Incubation temperature alters thermal preference and response to heat stress of broiler chickens along the rearing phase. Poult. Sci., 95(8): 1795-1804.

34. Loyau, T., Metayer-Coustard, S., Berri, C., Crochet, S., Cailleau-Audouin, E., Sannier, M., Chartrin, P., Praud, C., Hennequet-Antier, C., Rideau, N., Courousse, N., MignonGrasteau, S., Everaert, N., Duclos, M.J., Yahav, S., Tesseraud, S. and Collin, A. (2014) Thermal manipulation during embryogenesis has long-term effects on muscle and liver metabolism in fast-growing chickens. PLoS One, 9(9): e105339.

35. Al-Zghoul, M.B., Ismail, Z.B., Dalab, A.E., Al-Ramadan, A., Althnaian, T.A., Al-Ramadan, S.Y., Ali, A.M., Albokhadaim, I.F., Al Busadah, K.A., Eljarah, A., Jawasreh, K.I. and Hannon, K.M. (2015) Hsp90, Hsp60 and HSF-1 genes expression in muscle, heart and brain of thermally manipulated broiler chicken. Res. Vet. Sci., 99: 105-111.

36. Al-Zghoul, M.B., El-Bahr, S.M., Al-Rukibat, R.K., Dalab, A.E., Althnaian, T.A. and Al-Ramadan, S.Y. (2015) Biochemical and molecular investigation of thermal manipulation protocols during broiler embryogenesis and subsequent thermal challenge. BMC Vet. Res., 11: 292-300.

37. Al-Zghoul, M.B., Dalab, A.E., Ababneh, M.M., Jawasreh, K.I., Al Busadah, K.A. and Ismail, Z.B. (2013) Thermal manipulation during chicken embryogenesis results in enhanced Hsp70 gene expression and the acquisition of thermotolerance. Res. Vet. Sci., 95(2): 502-507.

38. Nichelmann, M., Höchel, J. and Tzschentke, B. (1999) Biological rhythms in birds development, insights and perspectives. Comp. Biochem. Physiol. A Mol. Integr. Physiol., 124(4): 429-437.

39. Dorner, G. (1973) Environment-dependent brain differentiation and fundamental processes of life. Acta Biol. Med. Ger., 33(2): 129-148.

40. Al-Zghoul, M.B. and Saleh, K.M.M. (2020) Effects of thermal manipulation of eggs on the response of jejunal mucosae to posthatch chronic heat stress in broiler chickens. Poult. Sci., 99(5): 2727-2735.

41. Al-Zghoul, M.B., Saleh, K.M.M. and Jaradat, Z.W. (2019) Expression of digestive enzyme and intestinal transporter genes during chronic heat stress in the thermally manipulated broiler chicken. Poult. Sci., 98(9): 4113-4122.

42. de Barros Moreira Filho, A.L., de Oliveira, C.J.B., de Oliveira, H.B., Campos, D.B., Guerra, R.R., Costa, F.G.P. and Givisiez, P.E.N. (2015) High incubation temperature and threonine dietary level improve ileum response against post-hatch Salmonella Enteritidis inoculation in broiler chicks. PLoS One, 10(7): e0131474.

43. Tzschentke, B. (2008) Monitoring the development of thermoregulation in poultry embryos and its influence by incubation temperature. Comput. Electron. Agric., 64(1): 61-71.

44. Molenaar, R., Reijrink, I., Meijerhof, R. and Van den Brand, H. (2010) Meeting embryonic requirements of broilers throughout incubation: A review. Rev. Bras. Cienc. Avic., 12(3): 137-148.

45. Piestun, Y., Shinder, D., Ruzal, M., Halevy, O. and Yahav, S. (2008) The effect of thermal manipulations during the development of the thyroid and adrenal axes on in-hatch and post-hatch thermoregulation. J. Therm. Biol., 33(7): 413-418.

46. Zaboli, G.R., Rahimi, S., Shariatmadari, F., Torshizi, M.A.K.,
Baghbanzadeh, A. and Mehri, M. (2016) Thermal manipulation during Pre and Post-Hatch on thermotolerance of male broiler chickens exposed to chronic heat stress. Poult. Sci., 96(2): 478-485.

47. Amjadian, T. and Shahir, M.H. (2020) Effects of repeated thermal manipulation of broiler embryos on hatchability, chick quality, and post-hatch performance. Int. J. Biometeorol., 64(12): 2177-2183.

48. Piestun, Y., Shinder, D., Ruzal, M., Halevy, O., Brake, J. and Yahav, S. (2008) Thermal manipulations during broiler embryogenesis: Effect on the acquisition of thermotolerance. Poult. Sci., 87(8): 1516-1525.

49. Collin, A., Berri, C., Tesseraud, S., Rodon, F.E.R., SkibaCassy, S., Crochet, S., Duclos, M.J., Rideau, N., Tona, K. and Buyse, J. (2007) Effects of thermal manipulation during early and late embryogenesis on thermotolerance and breast muscle characteristics in broiler chickens. Poult. Sci., 86(5): 795-800.

50. Yalçin, S., Özkan, S., Siegel, P., Yenisey, Ç. and Aksit, M. (2012) Manipulation of incubation temperatures to increase cold resistance of broilers: Influence on embryo development, organ weights, hormones and body composition. Poult. Sci. J., 49(2): 133-139.

51. Willemsen, H., Li, Y., Willems, E., Franssens, L., Wang, Y., Decuypere, E. and Everaert, N. (2011) Intermittent thermal manipulations of broiler embryos during late incubation and their immediate effect on the embryonic development and hatching process. Poult. Sci., 90(6): 1302-1312.

52. Sozcu, A. and Ipek, A. (2015) Acute and chronic eggshell temperature manipulations during hatching term influence hatchability, broiler performance, and ascites incidence. Poult. Sci., 94(2): 319-327.

53. Lourens, A., Van den Brand, H., Meijerhof, R. and Kemp, B. (2005) Effect of eggshell temperature during incubation on embryo development, hatchability, and post-hatch development. Poult. Sci., 84(6): 914-920.

54. Molenaar, R., Van den Anker, I., Meijerhof, R., Kemp, B. and Van den Brand, H. (2011) Effect of eggshell temperature and oxygen concentration during incubation on the developmental and physiological status of broiler hatchlings in the perinatal period. Poult. Sci., 90(6): 1257-1266.

55. Tona, K., Onagbesan, O., Bruggeman, V., Collin, A., Berri, C., Duclos, M.J., Tesseraud, S., Buyse, J., Decuypere, E. and Yahav, S. (2008) Effects of heat conditioning at d 16 to 18 of incubation or during early broiler rearing on embryo physiology, post-hatch growth performance and heat tolerance. Arch. Geflugelk., 72(2): 75-83.

56. Al-Rukibat, R.K., Al-Zghoul, M.B., Hananeh, W.M., Al-Natour, M.Q. and Abu-Basha, E.A. (2017) Thermal manipulation during late embryogenesis: Effect on body weight and temperature, thyroid hormones, and differential white blood cell count in broiler chickens. Poult. Sci., 96(1): 234-240.

57. Yalçin, S., Molayoğlu, H., Baka, M., Genin, O. and Pines, M. (2007) Effect of temperature during the incubation period on tibial growth plate chondrocyte differentiation and the incidence of tibial dyschondroplasia. Poult. Sci., 86(8): 1772-1783.

58. Hulet, R., Gladys, G., Hill, D., Meijerhof, R. and El-Shiekh, T. (2007) Influence of egg shell embryonic incubation temperature and broiler breeder flock age on post-hatch growth performance and carcass characteristics. Poult. Sci., 86(2): 408-412.

59. Narinç, D., Erdoğan, S., Tahtabiçen, E. and Aksoy, T. (2016) Effects of thermal manipulations during embryogenesis of broiler chickens on developmental stability, hatchability and chick quality. Animals, 10(8): 1328-1335.

60. Nyuiadzi, D., Berri, C., Dusart, L., Travel, A., Méda, B., Bouvarel, I., Guilloteau, L., Chartrin, P., Coustham, V. and Praud, C. (2020) Short cold exposures during incubation and postnatal cold temperature affect performance, breast meat quality, and welfare parameters in broiler chickens. 
Poult. Sci., 99(2): 857-868.

61. Al-Zghoul, M.B., Al-Natour, M.Q., Dalab, A.S., Alturki, O.I., Althnaian, T.I.I.I., Al-Ramadan, S.Y., Hannon, K.M. and El-Bahr, S.M. (2016) Thermal manipulation mid-term broiler chicken embryogenesis: Effect on muscle growth factors and muscle marker genes. Rev. Bras. Cienc. Avic., 18(4): 607-618.

62. Piestun, Y., Halevy, O. and Yahav, S. (2009) Thermal manipulations of broiler embryos--the effect on thermoregulation and development during embryogenesis. Poult. Sci., 88(12): 2677-2688

63. Hartley, R.S., Bandman, E. and Yablonka-Reuveni, Z. (1992) Skeletal muscle satellite cells appear during late chicken embryogenesis. Dev. Biol., 153(2): 206-216.

64. Halevy, O., Yahav, S. and Rozenboim, I. (2006) Enhancement of meat production by environmental manipulations in embryo and young broilers. Worlds Poult. Sci. J., 62(3): 485-497.

65. Piestun, Y., Yahav, S. and Halevy, O. (2015) Thermal manipulation during embryogenesis affects myoblast proliferation and skeletal muscle growth in meat-type chickens. Poult. Sci., 94(10): 2528-2536.

66. Loyau, T., Berri, C., Bedrani, L., Metayer-Coustard, S., Praud, C., Duclos, M.J., Tesseraud, S., Rideau, N., Everaert, N., Yahav, S., Mignon-Grasteau, S. and Collin, A. (2013) Thermal manipulation of the embryo modifies the physiology and body composition of broiler chickens reared in floor pens without affecting breast meat processing quality. Anim. Sci. J., 91(8): 3674-3685.

67. Piestun, Y., Halevy, O., Shinder, D., Ruzal, M., Druyan, S. and Yahav, S. (2011) Thermal manipulations during broiler embryogenesis improves post-hatch performance under hot conditions. J. Therm. Biol., 36(7): 469-474.

68. Piestun, Y., Shinder, D., Ruzal, M., Halevy, O. and Yadav, S. (2008b) The effect of thermal manipulations during the development of the thyroid and adrenal axes on in-hatch and post-hatch thermoregulation. Therm. Biol., 33(7): 413-418.

69. Piestun, Y., Shinder, D., Ruzal, M., Halevy, O., Brake, J. and Yahav, S. (2008a) Thermal manipulations during broiler embryogenesis: Effect on the acquisition of thermotolerance. Poult. Sci., 87(8): 1516-1525.

70. Al-Zghoul, M.B., Dalab, A.E.S., Yahya, I.E., Althnaian, T.A., Al-Ramadan, S.Y., Ali, A.M., Albokhadaim, I.F., El-Bahr, S.M., Al Busadah, K.A. and Hannon, K.M. (2015) Thermal manipulation during broiler chicken embryogenesis: Effect on mRNA expressions of Hsp108, Hsp70, Hsp47 and Hsf-3 during subsequent post-hatch thermal challenge. Res. Vet. Sci., 103: 211-217.

71. Bouchama, A. and Knochel, J.P. (2002) Heat stroke. N. Engl. J. Med., 346(25): 1978-1988.

72. Epstein, Y. and Roberts, W.O. (2011) The pathopysiology of heat stroke: An integrative view of the final common pathway. Scand. J. Med. Sci. Sports, 21(6): 742-748.

73. Lambert, G. (2009) Stress-induced gastrointestinal barrier dysfunction and its inflammatory effects. J. Anim. Sci., 87(Suppl 14): E101-E108.

74. Leon, L.R. and Helwig, B.G. (2010) Heat stroke: Role of the systemic inflammatory response. J. Appl. Physiol., 109(6): 1980-1988.

75. Peterson, L.W. and Artis, D. (2014) Intestinal epithelial cells: Regulators of barrier function and immune homeostasis. Nat. Rev. Immunol., 14(3): 141-153.

76. Lambert, G., Gisolfi, C.V., Berg, D.J., Moseley, P.L., Oberley, L.W. and Kregel, K.C. (2002) Selected contribution: Hyperthermia-induced intestinal permeability and the role of oxidative and nitrosative stress. J. Appl. Physiol., 92(4): 1750-1761.

77. Tsukita, S., Furuse, M. and Itoh, M. (2001) Multifunctional strands in tight junctions. Nat. Rev. Mol. Cell Biol., 2(4): 285-293

78. Schneeberger, E.E. and Lynch, R.D. (2004) The tight junction: A multifunctional complex. Am. J. Physiol. Cell
Physiol., 286(6): C1213-C1228.

79. Catalioto, R.M., Maggi, C.A. and Giuliani, S. (2011) Intestinal epithelial barrier dysfunction in disease and possible therapeutical interventions. Curr. Med. Chem., 18(3): 398-426.

80. Mandel, L.J., Bacallao, R. and Zampighi, G. (1993) Uncoupling of the molecular fence and paracellular gate functions in epithelial tight junctions. Nature, 361(6412): 552-555.

81. Farquhar, M.G. and Palade, G.E. (1963) Junctional complexes in various epithelia. J. Cell Biol., 17(2): 375-412.

82. Al-Zghoul, M.B., Saleh, K.M. and Ababneh, M.M.K. (2019) Effects of pre-hatch thermal manipulation and posthatch acute heat stress on the mRNA expression of interleukin-6 and genes involved in its induction pathways in 2 broiler chicken breeds. Poult. Sci., 99(4): 1805-1819.

83. Vinoth, A., Thirunalasundari, T., Shanmugam, M., Uthrakumar, A., Suji, S. and Rajkumar, U. (2017) Evaluation of DNA methylation and mRNA expression of heat shock proteins in thermal manipulated chicken. Cell Stress Chaperon, 23(2): 235-252.

84. Tarkhan, A.H., Saleh, K.M. and Al-Zghoul, M.B. (2020) HSF3 and Hsp70 expression during post-hatch cold stress in broiler chickens subjected to embryonic thermal manipulation. Vet. Sci., 7(2): 49.

85. Dokladny, K., Moseley, P.L. and Ma, T.Y. (2006) Physiologically relevant increase in temperature causes an increase in intestinal epithelial tight junction permeability. Am. J. Physiol. Gastrointest., 290(2): G204-G212.

86. Li, G.C. and Mak, J.Y. (1989) Re-induction of hsp70 synthesis: An assay for thermotolerance. Int. J. Hyperthermia, 5(3): 389-403.

87. Awad, W.A., Hess, C. and Hess, M. (2017) Enteric pathogens and their toxin-induced disruption of the intestinal barrier through alteration of tight junctions in chickens. Toxins, 9(2): 60.

88. Kaiser, P. (2010) Advances in avian immunology prospects for disease control: A review. Avian Path., 39(5): 309-324.

89. Gribar, S.C., Richardson, W.M., Sodhi, C.P. and Hackam, D.J. (2008) No longer an innocent bystander: Epithelial toll-like receptor signaling in the development of mucosal inflammation. Mol. Med., 14(9): 645-659.

90. Peterson, C.Y., Costantini, T.W., Loomis, W.H., Putnam, J.G., Wolf, P., Bansal, V., Eliceiri, B.P., Baird, A. and Coimbra, R. (2010) Toll-like receptor-4 mediates intestinal barrier breakdown after thermal injury. Surg. Infect., 11(2): 137-144.

91. Giansanti, F., Giardi, M. and Botti, D. (2006) Avian cytokines-an overview. Curr. Pharm. Des., 12(24): 3083-3099.

92. Wigley, P. and Kaiser, P. (2003) Avian cytokines in health and disease. Rev. Bras. Cienc. Avic., 5(1): 1-14.

93. Xing, Z., Gauldie, J., Cox, G., Baumann, H., Jordana, M., Lei, X.F. and Achong, M.K. (1998) IL-6 is an antiinflammatory cytokine required for controlling local or systemic acute inflammatory responses. J. Clin. Invest., 101(2): 311.

94. Phillips, N.A., Welc, S.S., Wallet, S.M., King, M.A. and Clanton, T.L. (2015) Protection of intestinal injury during heat stroke in mice by interleukin-6 pretreatment. J. Physiol., 593(3): 739-753.

95. Leon, L.R. (2007) Heat stroke and cytokines. Prog. Brain Res., 162: 481-524.

96. Welc, S.S., Phillips, N.A., Oca-Cossio, J., Wallet, S.M., Chen, D.L. and Clanton, T.L. (2012) Hyperthermia increases interleukin-6 in mouse skeletal muscle. Am. J. Physiol. Cell Physiol., 303(4): C455-C466.

97. Welc, S.S., Judge, A.R. and Clanton, T.L. (2013) Skeletal muscle interleukin-6 regulation in hyperthermia. $\mathrm{Am}$. J Physiol. Cell Physiol., 305(4): C406-C413.

98. Bosch, I., Xhaja, K., Estevez, L., Raines, G., Melichar, H., Warke, R.V., Fournier, M.V., Ennis, F.A. and Rothman, A.L. (2002) Increased production of interleukin- 8 in primary human monocytes and in human epithelial and endothelial 
cell lines after dengue virus challenge. J. Virol., 76(11): 5588-5597.

99. Rennekampff, H.O., Hansbrough, J.F., Kiessig, V., Doré, C., Sticherling, M. and Schröder, J. (2000) Bioactive interleukin- 8 is expressed in wounds and enhances wound healing. J. Surg. Res., 93(1): 41-54.

100. Cheng, C.Y., Tu, W.L., Wang, S.H., Tang, P.C., Chen, C.F., Chen, H.H., Lee, Y.P., Chen, S.E. and Huang, S.Y. (2015) Annotation of differential gene expression in small yellow follicles of a broiler-type strain of Taiwan country chickens in response to acute heat stress. PLoS One, 10(11): e0143418.

101. Prakasam, R., Fujimoto, M., Takii, R., Hayashida, V., Takaki, E., Tan, K., Wu, F., Inouye, S. and Nakai, A. (2013) Chicken ILon of differential gene. FEBS Lett., 587(21): 3541-3547.

102. Streetz, K.L., Luedde, T., Manns, M.P. and Trautwein, C. (2000) Interleukin 6 and liver regeneration. Gut, 47(2): 309-312.

103. Welc, S.S., Clanton, T.L., Dineen, S.M. and Leon, L.R. (2013) Heat stroke activates a stress-induced cytokine response in skeletal muscle. J. Appl. Physiol., 115(8): 1126-1137.

104. McFarland-Mancini, M.M., Funk, H.M., Paluch, A.M., Zhou, M., Giridhar, P.V., Mercer, C.A., Kozma, S.C. and Drew, A.F. (2010) Differences in wound healing in mice with deficiency of IL-6 versus IL-6 receptor. J. Immunol., 184(12): 7219-7228.

105. Heled, Y., Fleischmann, C. and Epstein, Y. (2013) Cytokines and their role in hyperthermia and heat stroke. J. Basic Clin. Physiol. Pharmacol., 24(2): 85-96.

106. Shini, S. and Kaiser, P. (2009) Effects of stress, mimicked by administration of corticosterone in drinking water, on the expression of chicken cytokine and chemokine genes in lymphocytes. Stress, 12(5): 388-399.

107. Shini, S., Shini, A. and Kaiser, P. (2010) Cytokine and chemokine gene expression profiles in heterophils from chickens treated with corticosterone. Stress, 13(3): 185-194.

108. Chaussé, A.M., Grépinet, O., Bottreau, E., Le Vern, Y., Menanteau, P., Trotereau, J., Robert, V., Wu, Z., Kerboeuf, D. and Beaumont, C. (2011) Expression of Toll-like receptor 4 and downstream effectors in selected cecal cell subpopulations of chicks resistant or susceptible to Salmonella carrier state. Infect. Immun., 79(8): 3445-3454.
109. Rossaint, R., Cerny, V., Coats, T.J., Duranteau, J., Fernández-Mondéjar, E., Gordini, G., Stahel, P.F., Hunt, B.J., Neugebauer, E. and Spahn, D.R. (2006) Key issues in advanced bleeding care in trauma. Shock, 26(4): 322-331.

110. McCarthy, C.G., Goulopoulou, S., Wenceslau, C.F., Spitler, K., Matsumoto, T. and Webb, R.C. (2013) Tolllike receptors and damage-associated molecular patterns: novel links between inflammation and hypertension. Am. J. Physiol. Heart Circ. Physiol., 306(2): H184-H196.

111. Asea, A., Rehli, M., Kabingu, E., Boch, J.A., Baré, O., Auron, P.E., Stevenson, M.A. and Calderwood, S.K. (2002) Novel signal transduction pathway utilized by extracellular HSP70 role of Toll-like receptor (TLR) 2 and TLR4. J. Biol. Chem., 277(17): 15028-15034.

112. Calderwood, S.K., Mambula, S.S., Gray, P.J. and Theriault, J.R. (2007) Extracellular heat shock proteins in cell signaling. FEBS Lett., 581(19): 3689-3694.

113. Qureshi, S., Banday, M.T., Shakeel, I., Adil, S., Mir, M.S., Beigh, Y.A. and Amin, U. (2016) Histomorphological studies of broiler chicken fed diets supplemented with either raw or enzyme-treated dandelion leaves and fenugreek seeds. Vet. World, 9(3): 269

114. Prakatur, I., Miskulin, M., Pavic, M., Marjanovic, K., Blazicevic, V., Miskulin, I. and Domacinovic, M. (2019) Intestinal morphology in broiler chickens supplemented with propolis and bee pollen. Animals, 9(6): 301 .

115. Hamedi, S., Rezaian, M. and Shomali, T. (2011) Histological changes of small intestinal mucosa of cocks due to sunflower meal single feeding. Am. J. Anim. Vet. Sci., 6(4): 171-175.

116. Izadi, H., Arshami, J., Golian, A. and Raji, M.R. (2013) Effects of chicory root powder on growth performance and histomorphometry of jejunum in broiler chicks. Vet. Res. Forum., 4(3):169-174.

117. Santos, R.R., Awati, A., Roubos-van den Hil, P.J., TersteegZijderveld, M.H., Koolmees, P.A. and Fink-Gremmels, J. (2015) Quantitative histo-morphometric analysis of heatstress-related damage in the small intestines of broiler chickens. Avian Pathol., 44(1): 19-22.

118. Shahir, M., Dilmagani, S. and Tzschentke, B. (2012) Earlyage cold conditioning of broilers: Effects of timing and temperature. Br. Poult. Sci., 53(4): 538-544. 